\title{
Bimetallic Iron-Palladium Catalyst System as a Lewis-Acid for the Synthesis of Novel Pharmacophores Based Indole Scaffold as Anticancer Agents
}

\author{
Mohammad Shahidul Islam ${ }^{1}{ }^{\circledR}$, M. Ali $^{1}$, Abdullah Mohammed Al-Majid ${ }^{1}$, Abdullah Saleh Alamary ${ }^{1}$, \\ Saeed Alshahrani ${ }^{1}$, Sammer Yousuf ${ }^{2}$, Muhammad Iqbal Choudhary ${ }^{2}$ and Assem Barakat ${ }^{1,3, * \text { (i) }}$ \\ 1 Department of Chemistry, College of Science, King Saud University, P.O. Box 2455, \\ Riyadh 11451, Saudi Arabia; mislam@ksu.edu.sa (M.S.I.); maly.c@ksu.edu.sa (M.A.); \\ amajid@ksu.edu.sa (A.M.A.-M.); alamary1401@yahoo.com (A.S.A.); chemistry99y@gmail.com (S.A.) \\ 2 H.E.J. Research Institute of Chemistry, International Center for Chemical and Biological Sciences, University \\ of Karachi, Karachi 75270, Pakistan; dr.sammer.yousuf@gmail.com (S.Y.); iqbal.choudhary@iccs.edu (M.I.C.) \\ 3 Department of Chemistry, Faculty of Science, Alexandria University, P.O. Box 426, Ibrahimia, \\ Alexandria 21321, Egypt \\ * Correspondence: ambarakat@ksu.edu.sa; Tel.: +966-11467-5901; Fax: +966-11467-5992
}

\section{check for}

updates

Citation: Islam, M.S.; Ali, M.; Al-Majid, A.M.; Alamary, A.S.; Alshahrani, S.; Yousuf, S.; Choudhary, M.I.; Barakat, A. Bimetallic Iron-Palladium Catalyst System as a Lewis-Acid for the Synthesis of Novel Pharmacophores Based Indole Scaffold as Anticancer Agents. Molecules 2021, 26, 2212. https:// doi.org/10.3390/molecules26082212

Academic Editor: David StC Black

Received: 18 March 2021

Accepted: 1 April 2021

Published: 12 April 2021

Publisher's Note: MDPI stays neutral with regard to jurisdictional claims in published maps and institutional affiliations.

Copyright: (c) 2021 by the authors. Licensee MDPI, Basel, Switzerland. This article is an open access article distributed under the terms and conditions of the Creative Commons Attribution (CC BY) license (https:/ / creativecommons.org/licenses/by/ $4.0 /)$.
Abstract: The Friedel-Crafts reaction between substituted indoles as nucleophiles with chalconesbased benzofuran and benzothiophene scaffolds was carried out by employing a highly efficient bimetallic iron-palladium catalyst system. This catalytic approach produced the desired bis-heteroaryl products with low catalyst loading, a simple procedure, and with acceptable yield. All synthesized indole scaffolds 3a-3s were initially evaluated for their cytotoxic effect against human fibroblast BJ cell lines and appeared to be non-cytotoxic. All non-cytotoxic compounds 3a-3s were then evaluated for their anticancer activities against cervical cancer HeLa, prostate cancer PC3, and breast cancer MCF-7 cell lines, in comparison to standard drug doxorubicin, with $\mathrm{IC}_{50}$ values $1.9 \pm 0.4 \mu \mathrm{M}$, $0.9 \pm 0.14 \mu \mathrm{M}$ and $0.79 \pm 0.05 \mu \mathrm{M}$, respectively, and appeared to be moderate to weak anticancer agents. Fluoro-substituted chalcone moiety-containing compounds, $\mathbf{3 b}$ appeared to be the most active member of the series against cervical HeLa $\left(\mathrm{IC}_{50}=8.2 \pm 0.2 \mu \mathrm{M}\right)$ and breast MCF-7 cancer cell line $\left(\mathrm{IC}_{50}=12.3 \pm 0.04 \mu \mathrm{M}\right)$, whereas 6-fluroindol-4-bromophenyl chalcone-containing compound 3e $\left(\mathrm{IC}_{50}=7.8 \pm 0.4 \mu \mathrm{M}\right)$ appeared to be more active against PC3 prostate cancer cell line.

Keywords: Friedel-Crafts reaction; Lewis acids; indoles; benzothiophene; benzofuran; anti-cancer activity

\section{Introduction}

Nitrogen heterocycles (natural and synthetic) are key components of several biochemical, and therefore possess interesting biological properties. Indoles are one such class of organic heterocyclic compounds that occur frequently as a privileged structural motif in many synthetic and natural products with versatile pharmacological activities [1]. In many cases they have widespread uses as cholesterol lowering agents, antiviral, antibacterial, antifungal, and as anticancer compounds [2]. Some of them regulate cellular signaling and numerous neuropsychological processes. The indole structures have a rich history in chemistry beginning with the study of dyes in the mid-19th century. Despite the reported toxicity of some indole-containing compounds, several of them possess clinically beneficial properties. The natural products vinblastine and vincristine, isolated from C. roseus [3], are active against leukemia, lymphoma, breast, lung and other cancers (Figure 1) [4]. Analogues of these compounds are in use for the treatment of a variety of cancers [5]. Numerous other indole-containing compounds have been shown to possess anti-cancer activity, as well as a myriad of other biological properties [6-8]. Because of the prevalence of the indole moiety in biologically active compounds, it is considered a "privileged structure" and that 
makes it a logical motif to improve biological activity of synthetic compounds [9]. The indole moiety is also found in many natural products and comprises a major subset for the alkaloid class of natural products. For example, ajmalicine is an anti-hypertensive alkaloid [10], asperazine has an unusual profile of cytotoxicity [11,12], and dragmacidin exhibits anti-tumor activity against P-388 cell lines with $\mathrm{IC}_{50}$ value of $15 \mu \mathrm{g} / \mathrm{mL}$, and $\mathrm{IC}_{50}$ of $1-10 \mu \mathrm{g} / \mathrm{mL}$ against MDAMB (human mammary), HCT-8 (human colon) and A-549 (human lung) cancer cell lines [13-15].

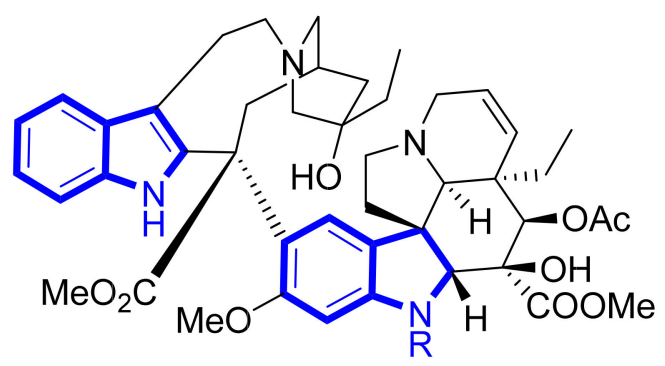

Vincristine $\mathrm{R}=\mathrm{Me}$ Vinblastine $\mathrm{R}=\mathrm{CHO}$ Anti-cancer alkaloids<smiles>COC(=O)C1=CO[C@@H](C)[C@H]2CN3CCC4c5ccccc5NC4[C@H]3C[C@H]12</smiles>

Ajmalicine Anti-Hypertensive alkaloid<smiles>[R3]c1ccc2cc([C@@H]3CN([R3])[C@@H](c4c[nH]c5c([R2])c([R3])cc([R])c45)CN3[R])[nH]c2c1</smiles>

Dragmacidin family Anti-cancer<smiles>O=C1N[C@H](Cc2ccccc2)C(=O)N2C1C[C@@]1(c3cccc4c(C[C@H]5NC(=O)[C@H](Cc6ccccc6)NC5=O)c[nH]c34)c3ccccc3N[C@H]21</smiles>

Asperazine

Leukemia anti-cancer agent

Figure 1. Bioactive compounds incorporating indole skeleton.

Cancer is one of the leading causes of death globally, with almost 10 million deaths worldwide in 2020 [16]. By 2030, it will become the leading cause of death [17]. 70\% of cancer deaths occur in middle or low-resource countries, where as $80 \%$ of cases are diagnosed too late for effective treatment. Cancer related deaths are increasing globally [17]

The heterogeneity of tumors, the lack of selectivity of drugs, and the development of drug resistance are some of the major obstacles impeding the effective cure of this deadly disease group. The fact of cell-death makes the situation even worse, because anti-cancer drugs follow first-order kinetics; that is, a fixed percentage, rather than a fixed number of cells are killed by a given treatment. Moreover, individual tumors may contain subpopulations of neoplastic cells that differ in terms of crucial features, any one of which could cause recurrence of the disease $[17,18]$.

Although significant progress has been made in cancer research; still urgent need for a new drug with the advantage of less side effect, safe, overcome drug resistance and high efficacy are challenge to the researcher [19].

In this manuscript, we describe the synthesis of the new hits based on indole/ benzofuran/benzothiophene analogues, along with the cytotoxities of the newly synthesized compounds against selected cancer cell lines. 


\section{Results and Discussion}

\subsection{Chemistry}

Michaël-type Friedel-Crafts addition of nucleophiles (especially indoles) with electrondeficient alkenes are fundamentally important chemical transformations [20-24]. These methods have extensive uses in the scientific work on a number of potential nucleophilic species. Stabilized carbanions, organometallic reagents, and heteroatom-based nucleophiles have all been applied to a range of Michael acceptors in previous years [20,21]. The desired chalcones 1a-11 in this study were synthesized by following our previous reported method by Barakat et al [23] (Figure 2). Next, the achiral Friedel-Crafts reaction was explored with the chalcones-based benzofuran or thiophene analogues and the substituted indole by employing Fe-Pd bimetallic catalyst system [23] in $\mathrm{MeOH}$ at $60{ }^{\circ} \mathrm{C}$ to afford the FriedelCrafts adducts. To check the productivity and the generality of this approach, the reaction of substituted indoles (indole 2a; 5-bromoindole $\mathbf{2} \mathbf{b}$; 6 -fluroroindole $2 \mathbf{c}$ ) and chalcones based benzofuran or thiophene analogues was carried out under the reaction conditions $(10 \mathrm{~mol} \%$ of $\mathrm{FeCl}_{3}, 10 \mathrm{~mol} \%$ of $\mathrm{PdCl}_{2}$ and $15 \mathrm{~mol} \%$ ethyl acetoacetate (EAA), 1.0 equiv. chalcone and 1.1 equiv. substituted indole in $\mathrm{CH}_{3} \mathrm{OH}$ at $60{ }^{\circ} \mathrm{C}$; Scheme 1). A range of heteroaryl enone substituents further demonstrated a broad substrate scope. Both electron-deficient and electron-rich heterocycles afforded the Friedel-Crafts products in high yield.

\section{Chalcone 1a-I}<smiles>O=C(/C=C/c1cc2ccccc2o1)c1ccccc1</smiles>

1a<smiles>O=C(/C=C/c1cc2ccccc2o1)c1ccc(F)cc1</smiles>

$1 b$<smiles>O=C(/C=C/c1cc2ccccc2o1)c1ccccc1[N+](=O)[O-]</smiles>

$1 e$<smiles>O=C(/C=C/c1cc2ccccc2s1)c1ccccc1</smiles><smiles>O=C(/C=C/c1cc2ccccc2s1)c1ccc(F)cc1</smiles>

$1 k$<smiles>O=C(/C=C/c1cc2ccccc2s1)c1ccc(Br)cc1</smiles><smiles>O=C(/C=C/c1cc2ccccc2o1)c1ccc(Br)cc1</smiles>

1c<smiles>COc1ccccc1C(=O)/C=C/c1cc2ccccc2o1</smiles><smiles>O=C(/C=C/c1cc2ccccc2s1)c1ccc(C(F)(F)F)cc1</smiles>

11

Indoles derivatives
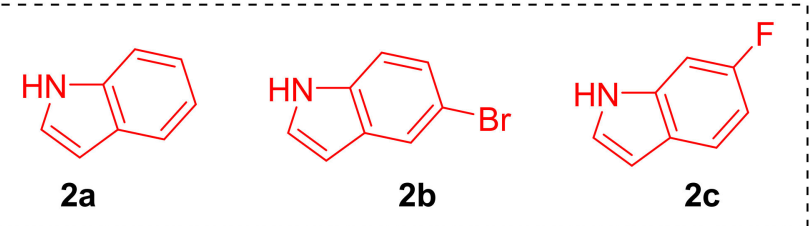

Figure 2. List of synthesized chalcones and substituted indoles utilized in this study. 
<smiles></smiles>

Chalcone 1a-l

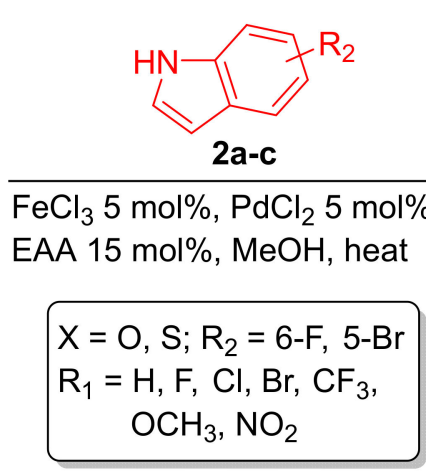

3a-s

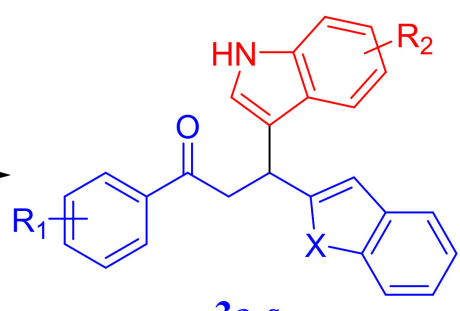

Scheme 1. Synthetic routes to 3a-3s. The reaction carried out with optimum reaction conditions as reported by Barakat et al. [23].

The structures of requisite Friedel-Crafts adducts were determined by using spectroscopic data, including ${ }^{1} \mathrm{H}-,{ }^{13} \mathrm{C}-\mathrm{NMR}$, Mass, and FT-IR spectroscopy.

\subsection{Anti-Cancer Activity}

All synthesized indoles 3a-3s were first evaluated for their cytotoxic effect against human fibroblast BJ cell line, and appeared to be either non-toxic (3a, 3i-3k, $3 \mathbf{r}$ and $\mathbf{3 s}$ ) or slightly toxic than (30\%) $\mathbf{3 b} \mathbf{b} \mathbf{3} \mathbf{i}$, and $\mathbf{3 f}-\mathbf{3 q}$ at a concentration of $30 \mu \mathrm{M}$. Based on the largely non-toxic nature of newly synthesized compounds against human fibroblast cell line compounds $\mathbf{3 a - 3 s}$ were further evaluated for their anticancer activities against HeLa, PC3, and MCF-7 cancer cell lines in comparison to standard drug doxorubicin, with $\mathrm{IC}_{50}$ values $1.9 \pm 0.4 \mu \mathrm{M}, 0.9 \pm 0.14 \mu \mathrm{M}$ and $0.79 \pm 0.05 \mu \mathrm{M}$, respectively, and appeared to be moderate to weak anticancer agents. Results of cytotoxic analysis and anti-cancer activities are summarized in Table 1.

Among series of substituted indoles and chalcone-based benzofurans compounds, 3a$3 \mathrm{~m}$ and $3 \mathbf{r}-3 \mathrm{~s}$, 6-fluoroindol-4-bromophenyl chalcone-containing compound $3 \mathbf{e}\left(\mathrm{IC}_{50}=7.8 \pm\right.$ $0.4 \mu \mathrm{M}$ ) appeared to be the most active anti-cancer agent against prostate PC 3 cancer cell line in comparison to non-substituted indoles and chalcone-based benzofuran ( $3 \mathrm{a}, \mathrm{IC}_{50}=$ $11.4 \pm 0.2 \mu \mathrm{M})$ and drug doxorubicin $\left(\mathrm{IC}_{50}=1.9 \pm 0.4 \mu \mathrm{M}\right)$. However, decrease in activity was observed in compounds $3 \mathbf{b}\left(\mathrm{IC}_{50}=22.2 \pm 0.4 \mu \mathrm{M}\right), 3 \mathbf{d}\left(\mathrm{IC}_{50}=26.3 \pm 0.8 \mu \mathrm{M}\right)$, and $3 \mathbf{f}$ $\left(\mathrm{IC}_{50}=27.0 \pm 0.4 \mu \mathrm{M}\right)$ having non-fluorinated indole moieties with fluoro-, bromo-, and chloro-substituted chalcone moieties, respectively. Similar pattern of decrease of activity was observed in compounds $3 \mathbf{g}\left(\mathrm{IC}_{50}=20.0 \pm 1.3 \mu \mathrm{M}\right)$, having chloro substituted phenyl rings of chalcones instead of bromo-substituted chalcone moiety of containing compound $3 \mathbf{e}\left(\mathrm{IC}_{50}=7.8 \pm 0.4 \mu \mathrm{M}\right)$. A complete loss of anticancer activity against PC 3 cells was observed when fluoro-substituted chalcone moieties were replaced by $o$-nitro phenyl ring of containing 3i. Anti-cancer potential was restored in indole and chalcone-based benzofuran derivative $3 \mathbf{j}\left(\mathrm{IC}_{50}=16.0 \pm 0.1 \mu \mathrm{M}\right)$ with bromo-substituted indole ring instead of fluorine substituent 3i. Among series of compounds having methoxy-substituted chalcone moiety $3 \mathbf{m}\left(\mathrm{IC}_{50}=19.3 \pm 0.1 \mu \mathrm{M}\right)$ appeared as weak anti-cancer agents whereas compounds $3 \mathbf{r}$ and $3 s$ appeared to be inactive. The pattern of activity of compound $3 \mathbf{f}\left(\mathrm{IC}_{50}=16.3 \pm 1.6 \mu \mathrm{M}\right)$ and $3 r$ (in active) clearly demonstrated the positional effect of methoxy substituent of the chalcone moiety towards anti-cancer activity. All members of the series of the indole and chalcone-based thiophene derivatives $\mathbf{3 n}-\mathbf{3 q}$, appeared as weak anti-cancer agents against prostate cancer PC3 cell line in comparison to doxorubicin $\left(\mathrm{IC}_{50}=1.9 \pm 0.4 \mu \mathrm{M}\right)$ as standard drug.

All synthesized substituted indole and chalcone-based benzofurans $\mathbf{3 a}-\mathbf{3} \mathbf{m}$ and $\mathbf{3 r}-\mathbf{3 s}$ were further evaluated for their anticancer activities against cervical cancer HeLa cell lines and appeared to be moderate to weak anticancer agents against standard doxorubicin $\left(\mathrm{IC}_{50}=0.9 \pm 0.14 \mu \mathrm{M}\right)$. Non-substituted indole and chalcone-based benzofurans 3a appeared as weak anti-cancer agent with $\mathrm{IC}_{50}=22.5 \pm 0.9 \mu \mathrm{M}$. However, substitution 
of fluorine on phenyl ring of chalcone moiety contributed towards drastic increase in anti-cancer potential as observed in $3 b\left(\mathrm{IC}_{50}=8.2 \pm 0.2 \mu \mathrm{M}\right)$, followed by gradual decrease in anti-cancer potential by various substituents on chalcone and indole moieties as observed in 6-bromoindol-4-flurophenyl chalcone-containing $3 \mathrm{c}\left(\mathrm{IC}_{50}=10.8 \pm 0.1 \mu \mathrm{M}\right)$, 4 bromophenyl chalcone-containing $3 \mathrm{~d}\left(\mathrm{IC}_{50}=12.6 \pm 0.4 \mu \mathrm{M}\right)$, 6-fluroindol-4-bromophenyl chalcone-containing $3 \mathbf{e}\left(\mathrm{IC}_{50}=13.6 \pm 0.4 \mu \mathrm{M}\right)$, 4-chlorophenyl chalcone-containing $3 \mathbf{f}$ $\left(\mathrm{IC}_{50}=11.9 \pm 0.2 \mu \mathrm{M}\right)$, 6-fluroindol-4-chlorophenyl chalcone-containing $3 \mathrm{~g}\left(\mathrm{IC}_{50}=14.7\right.$ $\pm 1.1 \mu \mathrm{M})$, 4-aminophenyl chalcone-containing $3 \mathrm{~h}\left(\mathrm{IC}_{50}=29.7 \pm 0.4 \mu \mathrm{M}\right), 6$-fluroindol-2nitrophenyl chalcone-containing $3 \mathbf{i}\left(\mathrm{IC}_{50}=15.2 \pm 0.6 \mu \mathrm{M}\right)$, 5-bromoroindol-2-nitrophenyl chalcone-containing $3 \mathbf{j}\left(\mathrm{IC}_{50}=17.3 \pm 0.7 \mu \mathrm{M}\right)$, 4-trifluoromethylphenyl chalcone-containing 3k $\left(\mathrm{IC}_{50}=14.9 \pm 0.6 \mu \mathrm{M}\right)$, 3-methoxyphenyl chalcone-containing $31\left(\mathrm{IC}_{50}=11.1 \pm 0.6 \mu \mathrm{M}\right)$, 6-fluoroindol-3-methoxyphenyl chalcone-containing $3 \mathrm{~m}\left(\mathrm{IC}_{50}=15.2 \pm 0.2 \mu \mathrm{M}\right)$, and 5bromoindol-2-methoxyphenyl chalcone-containing 3 s $\left(\mathrm{IC}_{50}=18.4 \pm 0.2 \mu \mathrm{M}\right)$. Similar activity pattern was observed in non-substituted indole and chalcone-based thiophene derivative $3 \mathrm{n}\left(\mathrm{IC}_{50}=12.4 \pm 0.2 \mu \mathrm{M}\right)$, 4-chlorophenyl chalcone-containing compound 3o $\left(\mathrm{IC}_{50}=13.8 \pm 0.3 \mu \mathrm{M}\right)$, 4-fluorophenyl chalcone-containing $3 \mathbf{p}\left(\mathrm{IC}_{50}=12.7 \pm 0.1 \mu \mathrm{M}\right)$, and 4-trifluoromethylphenyl chalcone-containing $3 \mathrm{q}\left(\mathrm{IC}_{50}=18.8 \pm 0.2 \mu \mathrm{M}\right.$ against cervical cancer cell line HeLa in comparison to doxorubicin $\left(\mathrm{IC}_{50}=1.9 \pm 0.4 \mu \mathrm{M}\right)$ as standard drug.

Many of the tested compounds appeared to be inactive against MCF-7 breast cancer cell lines, except 3b, 3c, 3f, 3m and 3s. Non-substituted indole and chalcone-based benzofurans 3a, appeared to be inactive against MCF-7 breast cancer cell lines; however, substitution of fluorine on phenyl ring of chalcone moiety contributed towards drastic increase in anti-cancer potential, as observed in $3 \mathbf{b}\left(\mathrm{IC}_{50}=12.37 \pm 0.04 \mu \mathrm{M}\right)$, followed by gradual decrease in anti-cancer potential due to various substituents on chalcone and indole moieties, as observed in 4-chlorophenyl chalcone-containing $\mathbf{3 f}\left(\mathrm{IC}_{50}=\right.$ $19.28 \pm 0.78 \mu \mathrm{M})$, 6-fluroindol-3-methoxyphenyl chalcone-containing $3 \mathrm{~m}\left(\mathrm{IC}_{50}=22.9 \pm\right.$ $0.43 \mu \mathrm{M})$, 6-bromoindol-4-flurophenyl chalcone-containing $3 \mathrm{c}\left(\mathrm{IC}_{50}=25.87 \pm 0.8 \mu \mathrm{M}\right)$, and 5-bromoindol-2-methoxyphenyl chalcone-containing compound $3 \mathrm{~s}\left(\mathrm{IC}_{50}=28.64 \pm\right.$ $0.3 \mu \mathrm{M})$ against standard doxorubicin $\left(\mathrm{IC}_{50}=0.79 \pm 0.4 \mu \mathrm{M}\right)$. All synthesized indole and chalcone-based thiophene derivatives $\mathbf{3 n}-\mathbf{3 q}$ appeared to be inactive against breast cancer cell line MCF-7.

The comparison of substituted indole and chalcone-based benzofurans ( $\mathbf{3 a}, \mathbf{3 b} \mathbf{3} \mathbf{3}$, and $3 \mathbf{k}$ ) with substituted indole and chalcone-based thiophenes (3r-3s) disclosed that nonsubstituted indole and chalcone-based benzofuran $3 a\left(\mathrm{IC}_{50}=11.4 \pm 0.2 \mu \mathrm{M}\right)$ and fluoro-, and chloro-substituted chalcone moieties, containing compounds $3 \mathbf{b}\left(\mathrm{IC}_{50}=22.2 \pm 0.5 \mu \mathrm{M}\right)$ and $3 \mathbf{g}\left(\mathrm{IC}_{50}=22.0 \pm 1.3 \mu \mathrm{M}\right)$, respectively, appeared to be more active against PC3 prostate cancer cell lines, in comparison to non-substituted indole and chalcone-based thiophene $\mathbf{3 r}$ $\left(\mathrm{IC}_{50}=20.4 \pm 0.4 \mu \mathrm{M}\right)$ and fluoro-, and chloro-substituted chalcone moieties, containing compounds $3 \mathrm{p}\left(\mathrm{IC}_{50}=27.6 \pm 0.5 \mu \mathrm{M}\right)$ and $3 \mathrm{~s}\left(\mathrm{IC}_{50}=29.7 \pm 0.5 \mu \mathrm{M}\right)$, respectively, that appeared to have more anti-cancer potential against cervical cancer HeLa cell line $3 \mathbf{r}\left(\mathrm{IC}_{50}\right.$ $=12.4 \pm 0.2 \mu \mathrm{M}), 3 \mathbf{o}\left(\mathrm{IC}_{50}=13.8 \pm 0.3 \mu \mathrm{M}\right)$ and $\left.3 \mathbf{p}\left(\mathrm{IC}_{50}=12.7 \pm 0.1 \mu \mathrm{M}\right)\right]$. Among fluoro-, and chloro-substituted chalcone-containing compounds $3 \mathbf{b}$ and $3 \mathbf{s}$, respectively. Whereas trifluoro-substituted chalcone-containing benzofuran $3 \mathrm{k}\left(\mathrm{IC}_{50}=14.9 \pm 0.6 \mu \mathrm{M}\right)$ showed more activity against cervical cancer HeLa cell line, in comparison to thiophene analogue $\left(\mathbf{3 q}, \mathrm{IC}_{50}=18.8 \pm 0.2 \mu \mathrm{M}\right)$. Among benzofurans $(\mathbf{3 a}, \mathbf{3 b}, \mathbf{3 g}$, and $\mathbf{3 k})$ and thiophene $\mathbf{3 r}-\mathbf{3 s}$ structural analogues, 4-fluorophenyl chalcone-containing $3 \mathbf{b}\left(\mathrm{IC}_{50}=12.37 \pm 0.04 \mu \mathrm{M}\right)$ appeared to be the only active member against MCF-7 breast cancer cell line. All results are summarized in Table 1. 
Table 1. The $\mathrm{IC}_{50}$ results of the synthesized against 4 cancer cell lines.

\begin{tabular}{|c|c|c|c|c|c|}
\hline \multirow{2}{*}{ Compound } & \multirow{2}{*}{$\begin{array}{c}\text { Structure } \\
3 a-3 s\end{array}$} & \multicolumn{4}{|c|}{ Cancer Type/Cell Line $\left(\mathrm{IC}_{50}, \mu \mathrm{M}\right)$} \\
\hline & & $\begin{array}{c}\text { Human fibroblast } \\
\text { BJ }\end{array}$ & PC3 & HeLa & MCF-7 \\
\hline $3 a$ & & NA & $11.4 \pm 0.2$ & $22.5 \pm 0.9$ & NA \\
\hline $3 b$ & & $>30$ & $22.2 \pm 0.5$ & $8.2 \pm 0.2$ & $12.37 \pm 0.04$ \\
\hline $3 c$ & & $>30$ & $21.9 \pm 1.5$ & $10.8 \pm 0.1$ & $25.87 \pm 0.80$ \\
\hline $3 d$ & & $>30$ & $26.3 \pm 0.8$ & $12.6 \pm 0.4$ & NA \\
\hline $3 e$ & & $>30$ & $7.8 \pm 0.4$ & $13.6 \pm 0.4$ & NA \\
\hline $3 f$ & & $>30$ & $27.0 \pm 0.4$ & $11.9 \pm 0.2$ & $19.28 \pm 0.78$ \\
\hline $3 g$ & & $>30$ & $20.0 \pm 1.3$ & $14.7 \pm 1.1$ & NA \\
\hline
\end{tabular}


Table 1. Cont.

\begin{tabular}{|c|c|c|c|c|c|}
\hline \multirow{2}{*}{ Compound } & \multirow{2}{*}{$\begin{array}{c}\text { Structure } \\
3 a-3 s\end{array}$} & \multicolumn{4}{|c|}{ Cancer Type/Cell Line $\left(\mathrm{IC}_{50}, \mu \mathrm{M}\right)$} \\
\hline & & $\begin{array}{c}\text { Human fibroblast } \\
\text { BJ }\end{array}$ & PC3 & HeLa & MCF-7 \\
\hline $3 \mathrm{~h}$ & & $>30$ & $29.7 \pm 0.4$ & $13.8 \pm 0.3$ & NA \\
\hline $3 \mathbf{i}$ & & NA & NA & $15.2 \pm 0.6$ & NA \\
\hline $3 \mathbf{j}$ & & NA & $16.0 \pm 0.1$ & $17.3 \pm 0.7$ & NA \\
\hline $3 k$ & & NA & NA & $14.9 \pm 0.6$ & NA \\
\hline 31 & & $>30$ & $16.3 \pm 1.6$ & $11.1 \pm 0.6$ & NA \\
\hline $3 m$ & & $>50$ & $19.3 \pm 0.1$ & $15.2 \pm 0.2$ & $22.93 \pm 0.43$ \\
\hline $3 n$ & & $>50$ & $20.4 \pm 0.4$ & $12.4 \pm 0.2$ & NA \\
\hline
\end{tabular}


Table 1. Cont.

\begin{tabular}{|c|c|c|c|c|c|}
\hline \multirow{2}{*}{ Compound } & \multirow{2}{*}{$\begin{array}{l}\text { Structure } \\
3 a-3 s\end{array}$} & \multicolumn{4}{|c|}{ Cancer Type/Cell Line $\left(\mathrm{IC}_{50}, \mu \mathrm{M}\right)$} \\
\hline & & $\begin{array}{c}\text { Human fibroblast } \\
\text { BJ }\end{array}$ & PC3 & HeLa & MCF-7 \\
\hline 30 & & $>50$ & $29.7 \pm 0.1$ & $13.8 \pm 0.3$ & NA \\
\hline $3 p$ & & $>50$ & $27.6 \pm 0.1$ & $12.7 \pm 0.1$ & NA \\
\hline $3 q$ & & $>50$ & $18.0 \pm 0.3$ & $18.8 \pm 0.2$ & NA \\
\hline $3 r$ & & NA & NA & NA & NA \\
\hline $3 s$ & & NA & NA & $18.4 \pm 0.2$ & $28.64 \pm 0.33$ \\
\hline & Doxorubi & NA & $1.9 \pm 0.4$ & $0.9 \pm 0.14$ & $0.79 \pm 0.05$ \\
\hline
\end{tabular}

$\mathrm{IC}_{50}(\mu \mathrm{M})$ was evaluated using MTT assay and \pm is the standard deviation from three independent experiments. NA: means that the tested compound did not show anticancer activity at $30 \mu \mathrm{M}$.

\section{Materials and Methods}

\subsection{General Procedure (GP1)}

Chalcones 1a-11 $(0.5 \mathrm{mmol})$, indoles $(0.55 \mathrm{mmol})$, and dry methanol $(20 \mathrm{~mL})$ were charged into a $100 \mathrm{~mL}$ round bottom flask, equipped with condenser under inert atmosphere. $\mathrm{FeCl}_{3}(5 \mathrm{~mol} \%), \mathrm{PdCl}_{2}(5 \mathrm{~mol} \%)$, and $15 \mathrm{~mol} \%$ of ethyl-acetoacetate (EAA) were added to the reaction mixture. Then the reaction was heated at $60-80^{\circ} \mathrm{C}$ for $2-3 \mathrm{~h}$. The reaction was monitored by TLC until the complete consumption of starting materials. Then the reaction mixture was allowed to cool and $20 \mathrm{~mL}$ of distilled water was added. The products were extracted in $\mathrm{CH}_{2} \mathrm{Cl}_{2}(3 \times 20 \mathrm{~mL})$ and the organics part were dried over anhydrous $\mathrm{Mg}_{2} \mathrm{SO}_{4}$. The organic phases were concentrated under reduced pressure and subjected to column chromatography using 100-200 mesh silica gel and 20-30\% Ethyl acetate in $n$-hexane to afford moderate to good yields (60-90\%). 


\subsection{Synthesis of 3-(Benzofuran-2-yl)-3-(1H-indol-3-yl)-1-phenylpropan-1-one (3a)}

Following the general procedure (GP1) chalcone 1a (124 mg, $0.5 \mathrm{mmol})$ and indole 2a (64 mg, $0.55 \mathrm{mmol}$ ) produces Friedel-Crafts product-3a (yield $159 \mathrm{mg}, 87 \%$ ); m.p. 114-115 ${ }^{\circ} \mathrm{C} ;{ }^{1} \mathrm{H}-\mathrm{NMR}\left(500 \mathrm{MHz}, \mathrm{DMSO}-d_{6}\right) \delta 10.97(\mathrm{~d}, J=2.4 \mathrm{~Hz}, 1 \mathrm{H}, \mathrm{NH}), 8.08-8.02$ (m, 2H, Ar- $\left.\underline{\mathrm{H}}\right)$, 7.66-7.60 (m, 2H, Ar- $\underline{\mathrm{H}}), 7.55-7.48$ (m, 3H, Ar- $\underline{\mathrm{H}}), 7.44-7.40$ (m, 1H, Ar- $\underline{\mathrm{H}}), 7.38-7.32$ (m, $2 \mathrm{H}, \mathrm{Ar}-\underline{\mathrm{H}}), 7.16(\mathrm{pd}, J=7.3,1.5 \mathrm{~Hz}, 2 \mathrm{H}, \mathrm{Ar}-\underline{\mathrm{H}}), 7.06(\mathrm{ddd}, J=8.1,7.0,1.2 \mathrm{~Hz}, 1 \mathrm{H}, \mathrm{Ar}-\underline{\mathrm{H}})$, $6.96(\mathrm{ddd}, J=7.9,6.9,1.0 \mathrm{~Hz}, 1 \mathrm{H}, \mathrm{Ar}-\underline{\mathrm{H}}), 6.70(\mathrm{~d}, J=1.0 \mathrm{~Hz}, 1 \mathrm{H}, \mathrm{Ar}-\underline{\mathrm{H}}), 5.12(\mathrm{t}, J=7.2$ $\mathrm{Hz}, 1 \mathrm{H}, \mathrm{CH}), 4.07\left(\mathrm{dd}, J=17.5,7.6 \mathrm{~Hz}, 1 \mathrm{H}, \mathrm{CH}_{2(\mathrm{a})}\right), 3.93\left(\mathrm{dd}, J=17.5,7.0 \mathrm{~Hz}, 1 \mathrm{H}, \mathrm{CH}_{2(\mathrm{~b})}\right)$; ${ }^{13}$ C-NMR (126 MHz, DMSO-d 6 ) $\delta 197.7$ (CO), 161.0, 153.9, 136.6, 136.3, 133.3, 128.7, 128.4, $128.1,126.1,123.3,122.9,122.6,121.1,120.5,118.7,118.6,114.3,111.6,110.7,101.8,41.9(\mathrm{CH})$, $31.8\left(\mathrm{CH}_{2}\right)$; IR $\left(\mathrm{KBr}, \mathrm{cm}^{-1}\right) v_{\max }=3404,3056,29.04,2848,1678,1589,1450,1415,1334,1253$; [Anal. Calcd. for $\mathrm{C}_{25} \mathrm{H}_{19} \mathrm{NO}_{2}$ : C, 82.17; H, 5.24; N, 3.83; Found: C, 82.29; H, 5.12; N, 3.65]; $\mathrm{LC} / \mathrm{MS}(\mathrm{ESI}, \mathrm{m} / z)$ : $366.15[\mathrm{M}+\mathrm{H}]^{+}$, exact mass 365.14 for $\mathrm{C}_{25} \mathrm{H}_{19} \mathrm{NO}_{2}$.

\subsection{Synthesis of 3-(Benzofuran-2-yl)-1-(4-fluorophenyl)-3-(1H-indol-3-yl)propan-1-one (3b)}

Following the general procedure (GP1) chalcone $\mathbf{1 b}(133 \mathrm{mg}, 0.5 \mathrm{mmol})$ indole $2 \mathrm{a}$ (64 mg, $0.55 \mathrm{mmol}$ ) produces Friedel-Crafts product-3b (yield $174 \mathrm{mg}, 91 \%$ ); m.p. 157-158 ${ }^{\circ} \mathrm{C} ;{ }^{1} \mathrm{H}-\mathrm{NMR}\left(500 \mathrm{MHz}, \mathrm{DMSO}-d_{6}\right) \delta 10.98(\mathrm{~d}, J=2.4 \mathrm{~Hz}, 1 \mathrm{H}, \mathrm{N} \underline{\mathrm{H}}), 8.16-8.10(\mathrm{~m}, 2 \mathrm{H}, \mathrm{Ar}-\underline{\mathrm{H}})$, $7.64(\mathrm{~d}, J=7.9 \mathrm{~Hz}, 1 \mathrm{H}, \mathrm{Ar}-\underline{\mathrm{H}}), 7.50$ (dd, $J=6.8,2.2 \mathrm{~Hz}, 1 \mathrm{H}, \mathrm{Ar}-\underline{\mathrm{H}}), 7.44-7.40$ (m, 1H, Ar- $\underline{\mathrm{H}})$, 7.38-7.32 (m, 4H, Ar- $\underline{\mathrm{H}}), 7.16(\mathrm{td}, J=7.0,1.6 \mathrm{~Hz}, 2 \mathrm{H}, \mathrm{Ar}-\underline{\mathrm{H}}), 7.06(\mathrm{ddd}, J=8.1,6.9,1.2 \mathrm{~Hz}, 1 \mathrm{H}$, $\operatorname{Ar}-\underline{\mathrm{H}}), 6.98-6.93(\mathrm{~m}, 1 \mathrm{H}, \mathrm{Ar}-\underline{\mathrm{H}}), 6.70(\mathrm{~d}, J=1.0 \mathrm{~Hz}, 1 \mathrm{H}, \mathrm{Ar}-\underline{\mathrm{H}}), 5.11(\mathrm{t}, J=7.2 \mathrm{~Hz}, 1 \mathrm{H}, \mathrm{CH})$, 4.07 (dd, $\left.J=17.5,7.5 \mathrm{~Hz}, 1 \mathrm{H}, \underline{\mathrm{CH}}_{2(\mathrm{a})}\right), 3.92\left(\mathrm{dd}, J=17.5,6.9 \overline{\mathrm{Hz}}, 1 \mathrm{H}, \underline{\mathrm{CH}}_{2(\mathrm{~b})}\right) ;{ }^{13} \mathrm{C}-\mathrm{NMR}(126$ MHz, DMSO- $\left.d_{6}\right) \delta 196.9(\mathrm{CO}), 166.6 \& 164.6\left(\mathrm{C}_{1}-\mathrm{F}, J_{\mathrm{C}-\mathrm{F}}=200.3 \mathrm{~Hz}\right), 161.5,154.4,136.9,133.9$, $133.9,131.7 \& 131.6\left(\mathrm{C}_{4}-\mathrm{F}, J_{\mathrm{C}-\mathrm{F}}=7.4 \mathrm{~Hz}\right), 128.9,126.6,123.9,123.5,123.10,121.6,121.1,119.2$ $\& 119.1\left(\mathrm{C}_{3}-\mathrm{F}, J_{\mathrm{C}-\mathrm{F}}=11.1 \mathrm{~Hz}\right), 116.3 \& 116.2\left(\mathrm{C}_{2}-\mathrm{F}, J_{\mathrm{C}-\mathrm{F}}=17.4 \mathrm{~Hz}\right), 114.8,112.1,111.3,102.4$, $42.4(\underline{\mathrm{CH}}), 32.3\left(\underline{\mathrm{CH}}_{2}\right)$; IR $\left(\mathrm{KBr}, \mathrm{cm}^{-1}\right) v_{\max }=3331,3055,2904,1677,1591,1502,1452,1363$, 1340, 1234, 1225; [Anal. Calcd. for $\mathrm{C}_{25} \mathrm{H}_{18} \mathrm{FNO}_{2}$ : C, 78.31; H, 4.73; N, 3.65; Found: C, 78.19; $\mathrm{H}, 4.65 ; \mathrm{N}, 3.52]$; LC/MS (ESI, $m / z): 384.14[\mathrm{M}+\mathrm{H}]^{+}$, exact mass 383.13 for $\mathrm{C}_{25} \mathrm{H}_{18} \mathrm{FNO}_{2}$.

3.4. Synthesis of 3-(Benzofuran-2-yl)-3-(5-bromo-1H-indol-3-yl)-1-(4-fluorophenyl)propan-1-one (3c)

The general procedure (GP1) chalcone $\mathbf{1 b}$ (133 mg, $0.5 \mathrm{mmol})$ 5-bromoindole $\mathbf{2 b}$ (108 mg, $0.55 \mathrm{mmol}$ ) produces Friedel-Crafts product-3c (yield $191 \mathrm{mg}, 83 \%$ ); m.p. $167-168{ }^{\circ} \mathrm{C}$; ${ }^{1} \mathrm{H}-\mathrm{NMR}\left(400 \mathrm{MHz}, \mathrm{DMSO}-d_{6}\right) \delta 11.21(\mathrm{~d}, J=2.4 \mathrm{~Hz}, 1 \mathrm{H}, \mathrm{NH}), 8.13(\mathrm{dd}, J=8.7,5.8 \mathrm{~Hz}, 2 \mathrm{H}$, Ar- $\underline{\mathrm{H}}), 7.82(\mathrm{~d}, J=2.0 \mathrm{~Hz}, 1 \mathrm{H}, \mathrm{Ar}-\underline{\mathrm{H}}), 7.54-7.50(\mathrm{~m}, 1 \mathrm{H}, \mathrm{Ar}-\underline{\mathrm{H}}), 7.47-7.41$ (m, 2H, Ar- $\underline{\mathrm{H}}), 7.34$ $(\mathrm{t}, J=8.9 \mathrm{~Hz}, 3 \mathrm{H}, \mathrm{Ar}-\underline{\mathrm{H}}), 7.22-7.12(\mathrm{~m}, 3 \mathrm{H}, \mathrm{Ar}-\underline{\mathrm{H}}), 6.73(\mathrm{~s}, \underline{\mathrm{H}}, \mathrm{Ar}-\underline{\mathrm{H}}), 5.10(\mathrm{t}, J=7.1 \mathrm{~Hz}, 1 \mathrm{H}$, $\mathrm{CH}), 4.06\left(\mathrm{dd}, J=17.7,7.3 \mathrm{~Hz}, 1 \mathrm{H}, \underline{\mathrm{CH}}_{2(\mathrm{a})}\right), 3.93\left(\mathrm{dd}, J=17.7,7.2 \mathrm{~Hz}, 1 \mathrm{H}, \mathrm{CH}_{2(\mathrm{~b})}\right)$; ${ }^{13} \mathrm{C}-\mathrm{NMR}$ $\left(101 \mathrm{MHz}, \mathrm{DMSO}-d_{6}\right) \delta 196.2$ (CO), $166.4 \& 163.9\left(\mathrm{C}_{1}-\mathrm{F}, J_{\mathrm{C}-\mathrm{F}}=250.7 \mathrm{~Hz}\right), 160.6,153.9,134.9$, 133.3, $131.2 \& 131.1\left(\mathrm{C}_{4}-\mathrm{F}, J_{\mathrm{C}-\mathrm{F}}=9.6 \mathrm{~Hz}\right), 128.4,127.9,124.8,123.6,123.4,122.6,120.9,120.6$, 115.8 \& $115.6\left(\mathrm{C}_{2}-\mathrm{F}, J_{\mathrm{C}-\mathrm{F}}=22.2 \mathrm{~Hz}\right), 114.2,113.6,111.3,110.7,101.9,41.9(\underline{\mathrm{CH}}), 31.4\left(\underline{\mathrm{CH}}_{2}\right)$; IR $\left(\mathrm{KBr}, \mathrm{cm}^{-1}\right) v_{\max }=3396,3066,2921,1675,1591,1504,1452,1413,1226$; [Anal. Calcd. for $\mathrm{C}_{25} \mathrm{H}_{17} \mathrm{BrFNO}_{2}$ : C, 64.95; H, 3.71; N, 3.03; Found: C, 65.17; H, 3.62; N, 2.93]; LC/MS (ESI, $m / z): 462.05[\mathrm{M}+\mathrm{H}]^{+}$, exact mass 461.04 for $\mathrm{C}_{25} \mathrm{H}_{17} \mathrm{BrFNO}_{2}$.

\subsection{Synthesis of 3-(Benzofuran-2-yl)-1-(4-bromophenyl)-3-(1H-indol-3-yl)propan-1-one (3d)}

Following the general procedure (GP1) chalcone 1c $(164 \mathrm{mg}, 0.5 \mathrm{mmol})$ indole 2a (64 mg, $0.55 \mathrm{mmol}$ ) produces Friedel-Crafts product-3d (yield $189 \mathrm{mg}, 85 \%$ ); m.p. 108-109

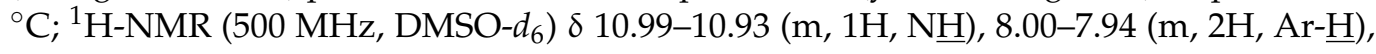
$7.73(\mathrm{~d}, J=8.5 \mathrm{~Hz}, 2 \mathrm{H}, \mathrm{Ar}-\underline{\mathrm{H}}), 7.62(\mathrm{~d}, J=8.0 \mathrm{~Hz}, 1 \mathrm{H}, \mathrm{Ar}-\underline{\mathrm{H}}), 7.51-7.47$ (m, 1H, Ar- $\underline{\mathrm{H}}), 7.41$ $(\mathrm{d}, J=7.6 \mathrm{~Hz}, 1 \mathrm{H}, \mathrm{Ar}-\underline{\mathrm{H}}), 7.37-7.31(\mathrm{~m}, 2 \mathrm{H}, \mathrm{Ar}-\underline{\mathrm{H}}), 7.16(\mathrm{td}, J=7.1,1.7 \mathrm{~Hz}, 2 \mathrm{H}, \mathrm{Ar}-\underline{\mathrm{H}}), 7.05(\mathrm{t}$, $J=7.6 \mathrm{~Hz}, 1 \mathrm{H}, \mathrm{Ar}-\underline{\mathrm{H}}), 6.95(\mathrm{t}, J=7.5 \mathrm{~Hz}, 1 \mathrm{H}, \mathrm{Ar}-\underline{\mathrm{H}}), 6.70(\mathrm{~s}, 1 \mathrm{H}, \mathrm{Ar}-\underline{\mathrm{H}}), 5.08(\mathrm{t}, J=7.3 \mathrm{~Hz}, 1 \mathrm{H}$, $\mathrm{C} \underline{\mathrm{H}}), 4.06\left(\mathrm{dd}, J=17.5,7.5 \mathrm{~Hz}, 1 \mathrm{H}, \mathrm{CH}_{2(\mathrm{a})}\right), 3.91\left(\mathrm{dd}, J=17.5,6.8 \mathrm{~Hz}, 1 \mathrm{H} \mathrm{CH}_{2(\mathrm{~b})}\right) ;{ }^{13} \mathrm{C}-\mathrm{NMR}$ $\left(126 \mathrm{MHz}, \mathrm{DMSO}-d_{6}\right) \delta 197.0$ (CO), 160.9, 153.9, 136.3, 135.5, 131.8, 130.2, 128.4, 127.4, 126.1, $123.4,123.0,122.6,121.1,120.5,118.7,118.6,114.2,111.6,110.7,101.9,41.9$ (ㅁH), $31.7\left(\underline{C H}_{2}\right)$; 
IR $\left(\mathrm{KBr}, \mathrm{cm}^{-1}\right) v_{\max }=3323,3057,2920,2852,1678,1580,1452,1394,1363,1338,1252,1197$; [Anal. Calcd. for $\mathrm{C}_{25} \mathrm{H}_{18} \mathrm{BrNO}_{2}$ : C, 67.58; H, 4.08; N, 3.15; Found: C, 67.45; H, 4.19; N, 3.01]; $\mathrm{LC} / \mathrm{MS}(\mathrm{ESI}, \mathrm{m} / z): 444.06[\mathrm{M}+\mathrm{H}]^{+}$, exact mass 443.05 for $\mathrm{C}_{25} \mathrm{H}_{18} \mathrm{BrNO}_{2}$.

3.6. Synthesis of 3-(Benzofuran-2-yl)-1-(4-bromophenyl)-3-(6-fluoro-1H-indol-3-yl)propan-1-one (3e)

Following the general procedure (GP1) chalcone 1c (164 mg, $0.5 \mathrm{mmol}) 6$-fluoroindole 2c (74 mg, $0.55 \mathrm{mmol})$ produces Friedel-Crafts product-3e (yield $166 \mathrm{mg}, 72 \%$ ); m.p. 123$124{ }^{\circ} \mathrm{C} ;{ }^{1} \mathrm{H}-\mathrm{NMR}\left(400 \mathrm{MHz}, \mathrm{DMSO}-\mathrm{d}_{6}\right) \delta 11.05(\mathrm{~d}, J=2.5 \mathrm{~Hz}, 1 \mathrm{H}, \mathrm{NH}), 7.97$ (d, $J=8.1$ $\mathrm{Hz}, 2 \mathrm{H}, \mathrm{Ar}-\underline{\mathrm{H}}), 7.72(\mathrm{~d}, J=8.1 \mathrm{~Hz}, 2 \mathrm{H}, \mathrm{Ar}-\underline{\mathrm{H}}), 7.62(\mathrm{dd}, J=8.8,5.3 \mathrm{~Hz}, 1 \mathrm{H}, \mathrm{Ar}-\underline{\mathrm{H}}), 7.50$ (d, $J=7.1 \mathrm{~Hz}, 1 \mathrm{H}, \mathrm{Ar}-\underline{\mathrm{H}}), 7.41(\mathrm{~d}, J=7.5 \mathrm{~Hz}, 1 \mathrm{H}, \mathrm{Ar}-\underline{\mathrm{H}}), 7.37(\mathrm{~d}, J=2.6 \mathrm{~Hz}, 1 \mathrm{H}, \mathrm{Ar}-\underline{\mathrm{H}}), 7.22-7.08$ $(\mathrm{m}, 3 \mathrm{H}, \mathrm{Ar}-\underline{\mathrm{H}}), 6.82(\mathrm{td}, J=9.4,2.5 \mathrm{~Hz}, 1 \mathrm{H}, \mathrm{Ar}-\underline{\mathrm{H}}), 6.71(\mathrm{~s}, 1 \mathrm{H}, \mathrm{Ar}-\underline{\mathrm{H}}), 5.08(\mathrm{t}, J=7.2 \mathrm{~Hz}, 1 \mathrm{H}$, $\mathrm{C} \underline{\mathrm{H}}), 4.06\left(\mathrm{dd}, J=17.6,7.4 \mathrm{~Hz}, 1 \mathrm{H}, \underline{\mathrm{CH}}_{2(\mathrm{a})}\right), 3.90\left(\mathrm{dd}, J=17.6,6.8 \mathrm{~Hz}, 1 \mathrm{H}, \underline{\mathrm{CH}}_{2(\mathrm{~b})}\right) ;{ }^{13} \mathrm{C}-\mathrm{NMR}$ $\left(126 \mathrm{MHz}, \mathrm{DMSO}-d_{6}\right) \delta 196.9$ (CO), 160.7, $159.8 \& 157.9\left(\mathrm{C}_{1}-\mathrm{F}, J_{\mathrm{C}-\mathrm{F}}=186.3 \mathrm{~Hz}\right), 153.9,136.2$ \& $136.1\left(\mathrm{C}_{3}-\mathrm{F}, J_{\mathrm{C}-\mathrm{F}}=10.3 \mathrm{~Hz}\right), 135.5,131.8,130.2,128.4,127.5,123.6 \& 123.6\left(\mathrm{C}_{4}-\mathrm{F}, J_{\mathrm{C}-\mathrm{F}}=2.6\right.$ $\mathrm{Hz}), 123.4,122.9,122.6,120.6,119.7 \& 119.7\left(\mathrm{C}_{5}-\mathrm{F}, J_{\mathrm{C}-\mathrm{F}}=8.2 \mathrm{~Hz}\right), 114.5,110.7,107.2 \& 106.9$ $\left(\mathrm{C}_{2}-\mathrm{F}, J_{\mathrm{C}-\mathrm{F}}=19.5 \mathrm{~Hz}\right), 101.9,97.6 \& 97.4\left(\mathrm{C}_{6}-\mathrm{F}, J_{\mathrm{C}-\mathrm{F}}=20.2 \mathrm{~Hz}\right), 41.9(\underline{\mathrm{CH}}), 31.6\left(\underline{\mathrm{CH}}_{2}\right)$; IR $(\mathrm{KBr}$, $\left.\mathrm{cm}^{-1}\right) v_{\max }=3359,2918,2850,1678,1624,1581,1454,1394,1336,1250$; [Anal. Calcd. for $\mathrm{C}_{25} \mathrm{H}_{17} \mathrm{BrFNO}_{2}$ : C, 64.95; H, 3.71; N, 3.03; Found: C, 64.84; H, 3.66; N, 3.21]; LC/MS (ESI, $m / z): 462.05[\mathrm{M}+\mathrm{H}]$, exact mass 461.04 for $\mathrm{C}_{25} \mathrm{H}_{17} \mathrm{BrFNO}_{2}$.

\subsection{Synthesis of 3-(Benzofuran-2-yl)-1-(4-chlorophenyl)-3-(1H-indol-3-yl)propan-1-one (3f)}

Following the general procedure (GP1) chalcone $1 \mathrm{~d}(141 \mathrm{mg}, 0.5 \mathrm{mmol})$ indole 2a (64 mg, $0.55 \mathrm{mmol}$ ) produces Friedel-Crafts product-3f (yield $158 \mathrm{mg}, 79 \%$ ); m.p. 126-127 ${ }^{\circ} \mathrm{C} ;{ }^{1} \mathrm{H}-\mathrm{NMR}\left(400 \mathrm{MHz}, \mathrm{DMSO}-d_{6}\right) \delta 10.98(\mathrm{~d}, J=2.4 \mathrm{~Hz}, 1 \mathrm{H}, \mathrm{NH}), 8.05(\mathrm{~d}, J=8.2 \mathrm{~Hz}$, $2 \mathrm{H}, \mathrm{Ar}-\underline{\mathrm{H}}), 7.63(\mathrm{~d}, J=8.0 \mathrm{~Hz}, 1 \mathrm{H}, \mathrm{Ar}-\underline{\mathrm{H}}), 7.58(\mathrm{~d}, J=8.6 \mathrm{~Hz}, 2 \mathrm{H}, \mathrm{Ar}-\underline{\mathrm{H}}), 7.52-7.47$ (m, 1H, Ar- $\underline{\mathrm{H}}), 7.44-7.40(\mathrm{~m}, 1 \mathrm{H}, \mathrm{Ar}-\underline{\mathrm{H}}), 7.38-7.33(\mathrm{~m}, 2 \mathrm{H}, \mathrm{Ar}-\underline{\mathrm{H}}), 7.16(\mathrm{t}, J=5.6 \mathrm{~Hz}, 2 \mathrm{H}, \mathrm{Ar}-\underline{\mathrm{H}}), 7.06$ $(\mathrm{t}, J=7.7 \mathrm{~Hz}, 1 \mathrm{H}, \mathrm{Ar}-\underline{\mathrm{H}}), 6.96(\mathrm{t}, J=7.4 \mathrm{~Hz}, 1 \mathrm{H}, \mathrm{Ar}-\underline{\mathrm{H}}), 6.70(\mathrm{~s}, 1 \mathrm{H}, \mathrm{Ar}-\underline{\mathrm{H}}), 5.10(\mathrm{t}, J=7.2$ $\mathrm{Hz}, 1 \mathrm{H}, \mathrm{CH}), 4.07$ (dd, $\left.J=17.6,7.4 \mathrm{~Hz}, 1 \mathrm{H}, \mathrm{CH}_{2(\mathrm{a})}\right), 3.93\left(\mathrm{dd}, J=17.6,7.1 \mathrm{~Hz}, 1 \mathrm{H}, \mathrm{CH}_{2(\mathrm{~b})}\right)$; ${ }^{13} \mathrm{C}-\mathrm{NMR}\left(101 \mathrm{MHz}\right.$, DMSO-d $\left.{ }_{6}\right) \delta 197.4$ (CO), 161.5, 154.5, 138.8, 136.9, 135.8, 130.6, 129.4, $128.9,126.7,123.9,123.6,123.2,121.7,121.1,119.3,119.1,114.8,112.1,111.3,102.5,42.6$ (․ㅡ), $32.3\left(\underline{\mathrm{CH}}_{2}\right)$; IR $\left(\mathrm{KBr}, \mathrm{cm}^{-1}\right) v_{\max }=3323,2935,2918,2854,1680,1585,1456,1396,1362,1340$, 1250; [Anal. Calcd. for $\mathrm{C}_{25} \mathrm{H}_{18} \mathrm{ClNO}_{2}$ : C, 75.09; H, 4.54; N, 3.50; Found: C, 75.23; H, 4.46; N, 3.39]; LC/MS (ESI, $m / z$ ): $400.14[\mathrm{M}+\mathrm{H}]^{+}$, exact mass 399.10 for $\mathrm{C}_{25} \mathrm{H}_{18} \mathrm{ClNO}_{2}$.

3.8. Synthesis of 3-(Benzofuran-2-yl)-1-(4-chlorophenyl)-3-(6-fluoro-1H-indol-3-yl)propan-1-one (3g)

Following the general procedure (GP1) chalcone 1d (141 mg, $0.5 \mathrm{mmol})$ 6-fluoroindole 2c (74 mg, $0.55 \mathrm{mmol}$ ) produces Friedel-Crafts product-3g (yield $146 \mathrm{mg}, 70 \%$ ); m.p. 112$113{ }^{\circ} \mathrm{C} ;{ }^{1} \mathrm{H}-\mathrm{NMR}\left(400 \mathrm{MHz}, \mathrm{DMSO}-d_{6}\right) \delta 11.08(\mathrm{~d}, J=2.4 \mathrm{~Hz}, 1 \mathrm{H}, \mathrm{NH}), 8.05(\mathrm{~d}, J=8.6 \mathrm{~Hz}$, $2 \mathrm{H}, \mathrm{Ar}-\underline{\mathrm{H}}), 7.64(\mathrm{dd}, J=8.8,5.6 \mathrm{~Hz}, 1 \mathrm{H}, \mathrm{Ar}-\underline{\mathrm{H}}), 7.57(\mathrm{~d}, J=8.3 \mathrm{~Hz}, 2 \mathrm{H}, \mathrm{Ar}-\underline{\mathrm{H}}), 7.50(\mathrm{~d}$, $J=7.4 \mathrm{~Hz}, 1 \mathrm{H}, \mathrm{Ar}-\underline{\mathrm{H}}), 7.44-7.36(\mathrm{~m}, 2 \mathrm{H}, \mathrm{Ar}-\underline{\mathrm{H}}), 7.21-7.10(\mathrm{~m}, 3 \mathrm{H}, \mathrm{Ar}-\underline{\mathrm{H}}), 6.84(\mathrm{td}, J=9.2$, $2.6 \mathrm{~Hz}, 1 \mathrm{H}, \mathrm{Ar}-\underline{\mathrm{H}}), 6.71(\mathrm{~s}, 1 \mathrm{H}, \mathrm{Ar}-\underline{\mathrm{H}}), 5.11(\mathrm{t}, J=7.2 \mathrm{~Hz}, 1 \mathrm{H}, \mathrm{C} \underline{\mathrm{H}}), 4.07(\mathrm{dd}, J=17.6,7.7 \mathrm{~Hz}$, $\left.1 \mathrm{H}, \underline{\mathrm{CH}}_{2(\mathrm{a})}\right), 3.92\left(\mathrm{dd}, J=17.6,7.1 \overline{\mathrm{Hz}}, 1 \mathrm{H}, \underline{\mathrm{CH}}_{2(\mathrm{~b})}\right) ;{ }^{13} \mathrm{C}-\mathrm{NMR}\left(101 \mathrm{MHz}, \mathrm{DMSO}-d_{6}\right) \delta 196.7$ (CO), 160.7, $160.0 \& 157.7\left(\mathrm{C}_{1}-\mathrm{F}, J_{\mathrm{C}-\mathrm{F}}=233.3 \mathrm{~Hz}\right), 153.9,138.3,136.3 \& 136.1\left(\mathrm{C}_{3}-\mathrm{F}, J_{\mathrm{C}-\mathrm{F}}=\right.$ $12.6 \mathrm{~Hz}), 135.2,130.0,128.8,128.4,123.6 \& 123.4\left(\mathrm{C}_{4}-\mathrm{F}, J_{\mathrm{C}-\mathrm{F}}=2.4 \mathrm{~Hz}\right), 122.9,122.6,120.6$, $119.8 \& 119.7\left(\mathrm{C}_{5}-\mathrm{F}, J_{\mathrm{C}-\mathrm{F}}=10.1 \mathrm{~Hz}\right), 114.5,110.7,107.2 \& 106.9\left(\mathrm{C}_{2}-\mathrm{F}, J_{\mathrm{C}-\mathrm{F}}=24.3 \mathrm{~Hz}\right), 101.9$, 97.6 \& $97.4\left(\mathrm{C}_{6}-\mathrm{F}, J_{\mathrm{C}-\mathrm{F}}=25.2 \mathrm{~Hz}\right), 41.9(\underline{\mathrm{CH}}), 31.7\left(\underline{\mathrm{CH}}_{2}\right) ; \mathrm{IR}\left(\mathrm{KBr}, \mathrm{cm}^{-1}\right) v_{\max }=3304,3028$, 2910, 2850, 1665, 1554, 1450, 1394, 1363, 1338, 1252; [Anal. Calcd. for $\mathrm{C}_{25} \mathrm{H}_{17} \mathrm{ClFNO}_{2}$ : C, 71.86; H, 4.10; N, 3.35; Found: C, 71.69; H, 4.25; N, 3.19]; LC/MS (ESI, $m / z): 418.10$ [M + H] ${ }^{+}$, exact mass 417.09 for $\mathrm{C}_{25} \mathrm{H}_{17} \mathrm{ClFNO}_{2}$. 
Following the general procedure (GP1) chalcone $\mathbf{1 i}(172 \mathrm{mg}, 0.5 \mathrm{mmol})$, indole $\mathbf{2 a}$ (108 mg, $0.55 \mathrm{mmol}$ ) produces Friedel-Crafts product-3h (yield $156 \mathrm{mg}, 68 \%$ ); m.p. 121 $122{ }^{\circ} \mathrm{C} ;{ }^{1} \mathrm{H}-\mathrm{NMR}\left(400 \mathrm{MHz}, \mathrm{DMSO}-d_{6}\right) \delta 10.97(\mathrm{~s}, 1 \mathrm{H}, \mathrm{NH}), 7.98(\mathrm{~d}, J=8.2 \mathrm{~Hz}, 2 \mathrm{H}, \mathrm{Ar}-\underline{\mathrm{H}})$, $7.72(\mathrm{dt}, J=18.7,9.0 \mathrm{~Hz}, 4 \mathrm{H}, \mathrm{Ar}-\underline{\mathrm{H}}), 7.54(\mathrm{~d}, J=8.0 \mathrm{~Hz}, 1 \mathrm{H}, \mathrm{Ar}-\underline{\mathrm{H}}), 7.41(\mathrm{~d}, J=2.5 \mathrm{~Hz}$, $1 \mathrm{H}, \mathrm{Ar}-\underline{\mathrm{H}}), 7.35-7.19(\mathrm{~m}, 4 \mathrm{H}, \mathrm{Ar}-\underline{\mathrm{H}}), 7.05(\mathrm{t}, J=7.6 \mathrm{~Hz}, 1 \mathrm{H}, \mathrm{Ar}-\underline{\mathrm{H}}), 6.92(\mathrm{t}, J=7.4 \mathrm{~Hz}, 1 \mathrm{H}$, Ar- $\underline{\mathrm{H}}), 5.23(\mathrm{t}, J=7.3 \mathrm{~Hz}, 1 \mathrm{H}, \mathrm{CH}), 4.01\left(\mathrm{dd}, J=10.8,7.1 \mathrm{~Hz}, 2 \mathrm{H}, \mathrm{CH}_{2}\right) ;{ }^{13} \mathrm{C}-\mathrm{NMR}(126 \mathrm{MHz}$, DMSO- $\left.d_{6}\right) \delta 197.0$ (CO), 150.76, 139.5, 138.5, 136.4, 135.6, 131.8, 130.2, 127.5, 126.1, 124.1, 123.6, 123.0, 122.5, 122.2, 121.2, 120.2, 118.7, 118.5, 116.8, 111.5, $44.5(\underline{\mathrm{CH}}), 33.4\left(\mathrm{CH}_{2}\right)$; IR $\left(\mathrm{KBr}, \mathrm{cm}^{-1}\right) v_{\max }=3335,3038,2907,2852,1678,1580,1455,1440,1360,1348,1255$; [Anal. Calcd. for $\mathrm{C}_{25} \mathrm{H}_{18}$ BrNOS: C, 65.22; $\mathrm{H}, 3.94 ; \mathrm{N}$, 3.04; Found: C, 65.04; $\mathrm{H}, 3.86$; N, 2.91]; LC/MS (ESI, $m / z$ ): $460.04[\mathrm{M}+\mathrm{H}]^{+}$, exact mass 459.03 for $\mathrm{C}_{25} \mathrm{H}_{18}$ BrNOS.

3.10. Synthesis of 3-(Benzofuran-2-yl)-3-(6-fluoro-1H-indol-3-yl)-1-(2-nitrophenyl)propan-1-one (3i)

Following the general procedure (GP1) chalcone 1e (147 mg, $0.5 \mathrm{mmol})$ and 6fluoroindole $2 \mathrm{c}(74 \mathrm{mg}, 0.55 \mathrm{mmol})$ produces Friedel-Crafts product-3i (yield $146 \mathrm{mg}$, 68\%); m.p. 139-140 ${ }^{\circ} \mathrm{C} ;{ }^{1} \mathrm{H}-\mathrm{NMR}\left(500 \mathrm{MHz}, \mathrm{DMSO}-d_{6}\right) \delta 11.10(\mathrm{~d}, J=2.5 \mathrm{~Hz}, 1 \mathrm{H}, \mathrm{NH}), 8.06$ $(\mathrm{dd}, J=8.0,1.2 \mathrm{~Hz}, 1 \mathrm{H}, \mathrm{Ar}-\underline{\mathrm{H}}), 7.78(\mathrm{td}, J=7.5,1.2 \mathrm{~Hz}, 1 \mathrm{H}, \mathrm{Ar}-\underline{\mathrm{H}}), 7.71$ (ddd, J = 12.9, 7.5, $1.6 \mathrm{~Hz}, 2 \mathrm{H}, \mathrm{Ar}-\underline{\mathrm{H}}), 7.61(\mathrm{dd}, J=8.8,5.4 \mathrm{~Hz}, 1 \mathrm{H}, \mathrm{Ar}-\underline{\mathrm{H}}), 7.54-7.50(\mathrm{~m}, 1 \mathrm{H}, \mathrm{Ar}-\underline{\mathrm{H}}), 7.44(\mathrm{dt}$, $J=7.2,1.3 \mathrm{~Hz}, 1 \mathrm{H}, \mathrm{Ar}-\underline{\mathrm{H}}), 7.40(\mathrm{~d}, J=2.5 \mathrm{~Hz}, 1 \mathrm{H}, \mathrm{Ar}-\underline{\mathrm{H}}), 7.22-7.12$ (m, 3H, Ar- $\underline{\mathrm{H}}), 6.83$ (ddd, $J=9.7,8.7,2.4 \mathrm{~Hz}, 1 \mathrm{H}, \mathrm{Ar}-\underline{\mathrm{H}}), 6.78-6.74(\mathrm{~m}, 1 \mathrm{H}, \mathrm{Ar}-\underline{\mathrm{H}}), 5.05(\mathrm{t}, J=7.1 \mathrm{~Hz}, 1 \mathrm{H}, \underline{\mathrm{CH}}), 4.01$ (dd, $\left.J=17.9,7.6 \mathrm{~Hz}, 1 \mathrm{H}, \mathrm{CH}_{2(\mathrm{a})}\right), 3.82\left(\mathrm{dd}, J=18.0,6.6 \mathrm{~Hz}, 1 \mathrm{H}, \underline{\mathrm{CH}}_{2(\mathrm{~b})}\right) ;{ }^{13} \mathrm{C}-\mathrm{NMR}(126 \mathrm{MHz}$, DMSO- $\left.d_{6}\right) \delta 199.5(\underline{\mathrm{CO}}), 160.1,159.8 \& 157.9\left(\mathrm{C}_{1}-\mathrm{F}, J_{\mathrm{C}-\mathrm{F}}=186.4 \mathrm{~Hz}\right), 154.0,146.2,136.3$ \& $136.2\left(\mathrm{C}_{3}-\mathrm{F}, J_{\mathrm{C}-\mathrm{F}}=10.0 \mathrm{~Hz}\right), 135.4,134.1,131.8,128.4 \& 128.4\left(\mathrm{C}_{4}-\mathrm{F}, J_{\mathrm{C}-\mathrm{F}}=3.8 \mathrm{~Hz}\right), 124.3$, $123.9,123.8,123.5,122.9,122.7,120.7,119.7 \& 119.6\left(C_{5}-\mathrm{F}, J_{C-F}=8.0 \mathrm{~Hz}\right), 114.1,110.8,107.3$ \& $107.1\left(\mathrm{C}_{2}-\mathrm{F}, J_{\mathrm{C}-\mathrm{F}}=19.5 \mathrm{~Hz}\right), 102.3,97.7 \& 97.5\left(\mathrm{C}_{6}-\mathrm{F}, J_{\mathrm{C}-\mathrm{F}}=20.0 \mathrm{~Hz}\right), 45.2(\underline{\mathrm{CH}}), 31.6\left(\mathrm{CH}_{2}\right)$; IR $\left(\mathrm{KBr}, \mathrm{cm}^{-1}\right) v_{\max }=3305,3062,2915,2858,1699,1621,1527,1452,1338,1255,1144,798$, 748, 696; [Anal. Calcd. for $\mathrm{C}_{25} \mathrm{H}_{17} \mathrm{FN}_{2} \mathrm{O}_{4}$ : C, 70.09; $\mathrm{H}, 4.00 ; \mathrm{N}, 6.54$; Found: C, 69.89; H, 4.11; $\mathrm{N}, 6.45]$; LC/MS (ESI, $m / z): 429.13[\mathrm{M}+\mathrm{H}]^{+}$, exact mass 428.12 for $\mathrm{C}_{25} \mathrm{H}_{17} \mathrm{FN}_{2} \mathrm{O}_{4}$.

3.11. Synthesis of 3-(Benzofuran-2-yl)-3-(5-bromo-1H-indol-3-yl)-1-(2-nitrophenyl)propan-1-one (3j)

Following the general procedure (GP1) chalcone 1 e (147 mg, $0.5 \mathrm{mmol})$ 5-bromoindole 2b (108 mg, $0.55 \mathrm{mmol})$ produces Friedel-Crafts product-3j (yield $154 \mathrm{mg}, 63 \%$ ); m.p. 173$174{ }^{\circ} \mathrm{C} ;{ }^{1} \mathrm{H}-\mathrm{NMR}\left(400 \mathrm{MHz}, \mathrm{DMSO}-d_{6}\right) \delta 11.25(\mathrm{~d}, J=2.6 \mathrm{~Hz}, 1 \mathrm{H}, \mathrm{NH}), 8.06(\mathrm{~d}, J=7.9 \mathrm{~Hz}$, 1H, Ar- $\underline{\mathrm{H}}), 7.84-7.76(\mathrm{~m}, 2 \mathrm{H}, \mathrm{Ar}-\underline{\mathrm{H}}), 7.73(\mathrm{~d}, J=7.6 \mathrm{~Hz}, 2 \mathrm{H}, \mathrm{Ar}-\underline{\mathrm{H}}), 7.54$ (d, J = 6.8 Hz, $1 \mathrm{H}, \operatorname{Ar}-\underline{\mathrm{H}}), 7.50-7.40(\mathrm{~m}, 2 \mathrm{H}, \operatorname{Ar}-\underline{\mathrm{H}}), 7.33(\mathrm{~d}, J=8.7 \mathrm{~Hz}, 1 \mathrm{H}, \operatorname{Ar}-\underline{\mathrm{H}}), 7.17$ (q, J = 7.3, 6.7 Hz, $3 \mathrm{H}, \mathrm{Ar}-\underline{\mathrm{H}}), 6.77(\mathrm{~s}, 1 \mathrm{H}, \mathrm{Ar}-\underline{\mathrm{H}}), 5.06(\mathrm{t}, J=6.9 \mathrm{~Hz}, 1 \mathrm{H}, \underline{\mathrm{CH}}), 4.02(\mathrm{dd}, J=18.0,7.5 \mathrm{~Hz}, 1 \mathrm{H}$, $\left.\mathrm{CH}_{2(\mathrm{a})}\right), 3.83\left(\mathrm{dd}, J=17.8,6.7 \mathrm{~Hz}, 1 \mathrm{H}, \mathrm{CH}_{2(\mathrm{~b})}\right) ;{ }^{13} \mathrm{C}-\mathrm{NMR}\left(126 \mathrm{MHz}, \mathrm{DMSO}-d_{6}\right) \delta 199.4(\underline{\mathrm{CO}})$, $159.9,153.9,146.1,135.3,134.9,133.9,131.7,128.4,128.4,127.8,124.9,124.2,123.7,123.5$, $122.6,120.8,120.6,113.7,113.6,111.3,110.7,102.2,45.1(\underline{\mathrm{CH}}), 31.2\left(\underline{\mathrm{CH}_{2}}\right) ; \mathrm{IR}\left(\mathrm{KBr}, \mathrm{cm}^{-1}\right)$ $v_{\max }=3324,3062,2918,2850,1695,1570,1519,1452,1334,1245,1099,879,854,791,746$, 694, 604; [Anal. Calcd. for $\mathrm{C}_{25} \mathrm{H}_{17} \mathrm{BrN}_{2} \mathrm{O}_{4}$ : C, 61.36; H, 3.50; N, 5.72; Found: C, 61.21; $\mathrm{H}$, 3.63; N, 5.62]; LC/MS (ESI, $m / z)$ : $489.05[\mathrm{M}+\mathrm{H}]$, exact mass 488.04 for $\mathrm{C}_{25} \mathrm{H}_{17} \mathrm{BrN}_{2} \mathrm{O}_{4}$.

\subsection{Synthesis of 3-(Benzofuran-2-yl)-3-(1H-indol-3-yl)-1-(2-nitrophenyl)propan-1-one (3k)}

Following the general procedure (GP1) chalcone 1e (147 mg, $0.5 \mathrm{mmol})$ indole 2a (64 mg, $0.55 \mathrm{mmol}$ ) produces Friedel-Crafts product-3k (yield $135 \mathrm{mg}, 66 \%$ ); m.p. 154 $155{ }^{\circ} \mathrm{C} ;{ }^{1} \mathrm{H}-\mathrm{NMR}\left(500 \mathrm{MHz}, \mathrm{DMSO}-d_{6}\right) \delta 11.01(\mathrm{~d}, J=2.5 \mathrm{~Hz}, 1 \mathrm{H}, \mathrm{N} \underline{\mathrm{H}}), 8.06(\mathrm{dd}, J=8.0$, $1.2 \mathrm{~Hz}, 1 \mathrm{H}, \mathrm{Ar}-\underline{\mathrm{H}}), 7.78$ (td, $J=7.5,1.2 \mathrm{~Hz}, 1 \mathrm{H}, \mathrm{Ar}-\underline{\mathrm{H}}), 7.74-7.68$ (m, 2H, Ar- $\underline{\mathrm{H}}), 7.60$ (d, $J=7.9 \mathrm{~Hz}, 1 \mathrm{H}, \mathrm{Ar}-\underline{\mathrm{H}}), 7.54-7.50(\mathrm{~m}, 1 \mathrm{H}, \mathrm{Ar}-\underline{\mathrm{H}}), 7.45-7.41$ (m, 1H, Ar- $\underline{\mathrm{H}}), 7.39-7.33$ (m, 2H, $\operatorname{Ar}-\underline{\mathrm{H}}), 7.17(\mathrm{pd}, J=7.2,1.4 \mathrm{~Hz}, 2 \mathrm{H}, \mathrm{Ar}-\underline{\mathrm{H}}), 7.08-7.03(\mathrm{~m}, 1 \mathrm{H}, \mathrm{Ar}-\underline{\mathrm{H}}), 6.95(\mathrm{t}, J=7.4 \mathrm{~Hz}, 1 \mathrm{H}$, Ar- $\underline{\mathrm{H}}), 6.75(\mathrm{~s}, 1 \mathrm{H}, \mathrm{Ar}-\underline{\mathrm{H}}), 5.05(\mathrm{t}, J=7.1 \mathrm{~Hz}, 1 \mathrm{H}, \mathrm{C} \underline{\mathrm{H}}), 4.01\left(\mathrm{dd}, J=17.9,7.8 \mathrm{~Hz}, 1 \mathrm{H}, \mathrm{CH}_{2(\mathrm{a})}\right)$, 
$3.82\left(\mathrm{dd}, J=17.9,6.4 \mathrm{~Hz}, 1 \mathrm{H}, \mathrm{CH}_{2(\mathrm{~b})}\right) ;{ }^{13} \mathrm{C}-\mathrm{NMR}\left(126 \mathrm{MHz}, \mathrm{DMSO}-d_{6}\right) \delta 199.6$ (CO), 160.3, 153.9, 146.2, 136.4, 135.4, 134.1, 131.8, 128.5, 128.4, 126.0, 124.3, 123.5, 123.2, 122.7, 121.2, $120.7,118.7,118.6,113.8,111.7,110.8,102.2,45.3(\underline{\mathrm{CH}}), 31.6\left(\mathrm{CH}_{2}\right) ; \mathrm{IR}\left(\mathrm{KBr}, \mathrm{cm}^{-1}\right) v_{\max }=$ $3310,3055,2901,2850,1684,1625,1530,145,1331,1253$; [Anal. Calcd. for $\mathrm{C}_{25} \mathrm{H}_{18} \mathrm{~N}_{2} \mathrm{O}_{4}$ : C, 73.16; H, 4.42; N, 6.83; Found: C, 73.10; H, 4.38; N, 6.79]; LC/MS (ESI, $m / z): 411.13$ [M + H] ${ }^{+}$, exact mass 410.13 for $\mathrm{C}_{25} \mathrm{H}_{18} \mathrm{~N}_{2} \mathrm{O}_{4}$.

\subsection{Synthesis of 3-(Benzofuran-2-yl)-3-(1H-indol-3-yl)-1-(3-methoxyphenyl)propan-1-one (31)}

Following the general procedure (GP1) chalcone $1 \mathrm{~g}(139 \mathrm{mg}, 0.5 \mathrm{mmol})$ indole $\mathbf{2 a}$ (64 mg, $0.55 \mathrm{mmol}$ ) produces Friedel-Crafts product-31 (yield $162 \mathrm{mg}, 82 \%$ ); m.p. 162 $163{ }^{\circ} \mathrm{C} ;{ }^{1} \mathrm{H}-\mathrm{NMR}\left(500 \mathrm{MHz}, \mathrm{DMSO}-d_{6}\right) \delta 10.97(\mathrm{~d}, J=2.5 \mathrm{~Hz}, 1 \mathrm{H}, \mathrm{N} \underline{\mathrm{H}}), 7.68-7.61(\mathrm{~m}, 2 \mathrm{H}$, Ar- $\underline{\mathrm{H}}), 7.52-7.47$ (m, 2H, Ar- $\underline{\mathrm{H}}), 7.46-7.40(\mathrm{~m}, 2 \mathrm{H}, \mathrm{Ar}-\underline{\mathrm{H}}), 7.37-7.33$ (m, 2H, Ar- $\underline{\mathrm{H}})$, 7.21-7.14 $(\mathrm{m}, 3 \mathrm{H}, \mathrm{Ar}-\underline{\mathrm{H}}), 7.05$ (ddd, $J=8.2,7.0,1.2 \mathrm{~Hz}, 1 \mathrm{H}, \mathrm{Ar}-\underline{\mathrm{H}}), 6.95(\mathrm{ddd}, J=8.0,7.0,1.0 \mathrm{~Hz}$, $1 \mathrm{H}, \mathrm{Ar}-\underline{\mathrm{H}}), 6.70(\mathrm{~d}, J=1.0 \mathrm{~Hz}, 1 \mathrm{H}, \mathrm{Ar}-\underline{\mathrm{H}}), 5.10(\mathrm{t}, J=7.2 \mathrm{~Hz}, 1 \mathrm{H}, \mathrm{CH}), 4.04(\mathrm{dd}, J=17.5$, $\left.7.5 \mathrm{~Hz}, 1 \mathrm{H}, \mathrm{CH}_{2(\mathrm{a})}\right), 3.93\left(\mathrm{dd}, J=17.5,7.0 \mathrm{~Hz}, 1 \mathrm{H}, \mathrm{CH}_{2(\mathrm{~b})}\right), 3.79\left(\mathrm{~s}, 3 \mathrm{H}, \mathrm{OCH}_{3}\right) ;{ }^{13} \mathrm{C}-\mathrm{NMR}$ $\left(126 \mathrm{MHz}, \mathrm{DMSO}-d_{6}\right) \delta 197.5$ (CO), 161.0, 159.4, 153.9, 138.0, 136.3, 129.9, 128.4, 126.1, 123.3, 123.0, 122.5, 121.1, 120.6, 120.5, 119.4, 118.7, 118.5, 114.2, 112.4, 111.6, 110.7, 101.8, 55.3 $\left(\mathrm{OCH}_{3}\right), 42.0(\underline{\mathrm{CH}}), 31.8\left(\mathrm{CH}_{2}\right) ; \mathrm{IR}\left(\mathrm{KBr}, \mathrm{cm}^{-1}\right) v_{\max }=3392,3055,2960,2916,2852,1674$, 1591, 1452,1423, 1333, 1265, 1190, 1161, 1095, 1008, 813, 790, 744, 609, 544; [Anal. Calcd. for $\mathrm{C}_{26} \mathrm{H}_{21} \mathrm{NO}_{3}$ : C, 78.97; H, 5.35; N, 3.54; Found: $\left.\mathrm{C}, 79.13 ; \mathrm{H}, 5.25 ; \mathrm{N}, 3.44\right]$; LC/MS (ESI, $m / z$ ): $396.16[\mathrm{M}+\mathrm{H}]$, exact mass 395.15 for $\mathrm{C}_{26} \mathrm{H}_{21} \mathrm{NO}_{3}$.

\subsection{Synthesis of 3-(Benzofuran-2-yl)-3-(6-fluoro-1H-indol-3-yl)-1-(3-} methoxyphenyl) propan-1-one (3m)

Following the general procedure (GP1) chalcone $1 \mathrm{~g}(139 \mathrm{mg}, 0.5 \mathrm{mmol})$ 6- fluoroindole 2c (74 mg, $0.55 \mathrm{mmol}$ ) produces Friedel-Crafts product-3m (yield $153 \mathrm{mg}, 74 \%$ ); m.p. 154$155^{\circ} \mathrm{C} ;{ }^{1} \mathrm{H}-\mathrm{NMR}\left(400 \mathrm{MHz}, \mathrm{DMSO}-d_{6}\right) \delta 11.04(\mathrm{~d}, J=2.4 \mathrm{~Hz}, 1 \mathrm{H}, \mathrm{NH}), 7.67-7.58(\mathrm{~m}, 2 \mathrm{H}$, Ar- $\underline{\mathrm{H}}), 7.53-7.46(\mathrm{~m}, 2 \mathrm{H}, \mathrm{Ar}-\underline{\mathrm{H}}), 7.46-7.40(\mathrm{~m}, 2 \mathrm{H}, \mathrm{Ar}-\underline{\mathrm{H}}), 7.36(\mathrm{~d}, J=2.5 \mathrm{~Hz}, 1 \mathrm{H}, \mathrm{Ar}-\underline{\mathrm{H}})$, 7.22-7.09 (m, 4H, Ar- $\underline{\mathrm{H}}), 6.82(\mathrm{td}, J=9.4,2.5 \mathrm{~Hz}, 1 \mathrm{H}, \mathrm{Ar}-\underline{\mathrm{H}}), 6.71(\mathrm{~s}, 1 \mathrm{H}, \mathrm{Ar}-\underline{\mathrm{H}}), 5.08(\mathrm{t}$, $J=7.1 \mathrm{~Hz}, 1 \mathrm{H}, \mathrm{C} \underline{\mathrm{H}}), 4.03\left(\mathrm{dd}, J=17.5,7.5 \mathrm{~Hz}, 1 \mathrm{H}, \mathrm{CH}_{2(\mathrm{a})}\right), 3.95-3.87\left(\mathrm{~m}, 1 \mathrm{H}, \mathrm{CH}_{2(\mathrm{~b})}\right), 3.79(\mathrm{~s}$, $\left.3 \mathrm{H}, \mathrm{CH}_{3}\right) ;{ }^{13} \mathrm{C}-\mathrm{NMR}\left(126 \mathrm{MHz}\right.$, DMSO- $\left.d_{6}\right) \delta 197.5$ (ㅇ) $), 160.8,159.4,159.78 \& 157.9\left(\mathrm{C}_{1}-\mathrm{F}\right.$, $\left.J_{\mathrm{C}-\mathrm{F}}=186.0 \mathrm{~Hz}\right), 153.9,137.9,136.2 \& 136.1\left(\mathrm{C}_{3}-\mathrm{F}, J_{\mathrm{C}-\mathrm{F}}=10.1 \mathrm{~Hz}\right), 129.9,128.4,123.7,123.4$, 123.0, 122.6, $120.6 \& 120.6\left(\mathrm{C}_{4}-\mathrm{F}, J_{\mathrm{C}-\mathrm{F}}=7.4 \mathrm{~Hz}\right), 119.7 \& 119.6\left(\mathrm{C}_{5}-\mathrm{F}, J_{\mathrm{C}-\mathrm{F}}=8.1 \mathrm{~Hz}\right), 119.5$, $114.5,112.5,110.7,107.2 \& 106.9\left(C_{2}-\mathrm{F}, J_{\mathrm{C}-\mathrm{F}}=19.4 \mathrm{~Hz}\right), 101.9,97.6 \& 97.4\left(\mathrm{C}_{6}-\mathrm{F}, J_{\mathrm{C}-\mathrm{F}}=20.3\right.$ $\mathrm{Hz}), 55.3\left(\mathrm{OCH}_{3}\right), 42.0(\mathrm{CH}), 31.7\left(\mathrm{CH}_{2}\right) ; \mathrm{IR}\left(\mathrm{KBr}, \mathrm{cm}^{-1}\right) v_{\max }=3409,3053,2922,2836$, 1666, 1513, 1483, 1454, 1430, 1286, 1244, 1163, 1101, 1016, 806, 740, 586; [Anal. Calcd. for $\mathrm{C}_{26} \mathrm{H}_{20} \mathrm{FNO}_{3}$ : C, 75.53; H, 4.88; N, 3.39; Found: C, 75.41; H, 4.99; N, 3.27]; LC/MS (ESI, $m / z): 414.15[\mathrm{M}+\mathrm{H}]^{+}$, exact mass 413.14 for $\mathrm{C}_{26} \mathrm{H}_{20} \mathrm{FNO}_{3}$.

\subsection{Synthesis of 3-(Benzo[b]thiophen-2-yl)-3-(1H-indol-3-yl)-1-phenylpropan-1-one (3n)}

Following the general procedure (GP1) chalcone $\mathbf{1 h}(132 \mathrm{mg}, 0.5 \mathrm{mmol})$ indole 2a (64 mg, $0.55 \mathrm{mmol}$ ) produces Friedel-Crafts product-3n (yield $164 \mathrm{mg}, 86 \%$ ); m.p. 159-160 ${ }^{\circ} \mathrm{C} ;{ }^{1} \mathrm{H}-\mathrm{NMR}\left(400 \mathrm{MHz}, \mathrm{DMSO}-d_{6}\right) \delta 10.90(\mathrm{~s}, 1 \mathrm{H}, \mathrm{N} \underline{\mathrm{H}}), 7.97$ (d, J = 7.7 Hz, 2H, Ar- $\underline{\mathrm{H}}$ ), 7.68 $(\mathrm{d}, J=8.1 \mathrm{~Hz}, 1 \mathrm{H}, \mathrm{Ar}-\underline{\mathrm{H}}), 7.60(\mathrm{~d}, J=8.0 \mathrm{~Hz}, 1 \mathrm{H}, \mathrm{Ar}-\underline{\mathrm{H}}), 7.54(\mathrm{t}, J=7.4 \mathrm{~Hz}, 1 \mathrm{H}, \mathrm{Ar}-\underline{\mathrm{H}}), 7.50$ $7.40(\mathrm{~m}, 3 \mathrm{H}, \mathrm{Ar}-\underline{\mathrm{H}}), 7.35(\mathrm{~s}, 1 \mathrm{H}, \mathrm{Ar}-\underline{\mathrm{H}}), 7.30-7.22(\mathrm{~m}, 2 \mathrm{H}, \mathrm{Ar}-\underline{\mathrm{H}}), 7.19(\mathrm{t}, J=7.5 \mathrm{~Hz}, 1 \mathrm{H}, \mathrm{Ar}-\underline{\mathrm{H}})$, $7.13(\mathrm{t}, J=7.6 \mathrm{~Hz}, 1 \mathrm{H}, \mathrm{Ar}-\underline{\mathrm{H}}), 6.98(\mathrm{t}, J=7.7 \mathrm{~Hz}, 1 \mathrm{H}, \mathrm{Ar}-\underline{\mathrm{H}}), 6.86(\mathrm{t}, J=7.5 \mathrm{~Hz}, 1 \mathrm{H}, \mathrm{Ar}-\underline{\mathrm{H}})$, $5.19(\mathrm{t}, J=7.2 \mathrm{~Hz}, 1 \mathrm{H}, \mathrm{C} \underline{\mathrm{H}}), 4.02-3.87\left(\mathrm{~m}, 2 \mathrm{H}, \mathrm{C}_{2}\right) ;{ }^{13} \mathrm{C}-\mathrm{NMR}\left(101 \mathrm{MHz}\right.$, DMSO- $\left.d_{6}\right) \delta 197.8$ (CO), 150.9, 139.6, 138.6, 136.7, 136.475, 133.4, 128.7, 128.1, 126.2, 124.1, 123.7, 122.9, 122.4, $122.1,121.1,120.2,118.8,118.6,116.9,111.5,44.6(\mathrm{CH}), 33.4\left(\mathrm{CH}_{2}\right) ; \mathrm{IR}\left(\mathrm{KBr}, \mathrm{cm}^{-1}\right) v_{\max }=$ 3427, 3394, 3053, 2885, 1668, 1597, 1450, 1334, 1265, 1194; [Anal. Calcd. for $\mathrm{C}_{25} \mathrm{H}_{19} \mathrm{NOS}$ : $\mathrm{C}$, 78.71; H, 5.02; N, 3.67; Found: C, 78.62; H, 5.17; N, 3.61]; LC/MS (ESI, $m / z): 382.13$ [M + H] ${ }^{+}$, exact mass 381.12 for $\mathrm{C}_{25} \mathrm{H}_{19} \mathrm{NOS}$. 
3.16. Synthesis of 3-(Benzo[b]thiophen-2-yl)-1-(4-chlorophenyl)-3-(1H-indol-3-yl)propan-1-one (3o)

Following the general procedure (GP1) chalcone $\mathbf{1 j}(149 \mathrm{mg}, 0.5 \mathrm{mmol})$ indole 2a (64 mg, $0.55 \mathrm{mmol}$ ) produces Friedel-Crafts product-3o (yield $160 \mathrm{mg}, 77 \%$ ); m.p. 150$151{ }^{\circ} \mathrm{C} ;{ }^{1} \mathrm{H}-\mathrm{NMR}\left(400 \mathrm{MHz}, \mathrm{DMSO}-d_{6}\right) \delta 10.99(\mathrm{~d}, J=2.5 \mathrm{~Hz}, 1 \mathrm{H}, \mathrm{NH}), 8.09-8.03$ (m, 2H, $\operatorname{Ar}-\underline{\mathrm{H}}), 7.76(\mathrm{~d}, J=8.0 \mathrm{~Hz}, 1 \mathrm{H}, \mathrm{Ar}-\underline{\mathrm{H}}), 7.69$ (d, J = 7.9 Hz, 1H, Ar- $\underline{\mathrm{H}}), 7.57$ (dd, J = 11.7, 8.4 Hz, $3 \mathrm{H}, \mathrm{Ar}-\underline{\mathrm{H}}), 7.43(\mathrm{~d}, J=2.7 \mathrm{~Hz}, 1 \mathrm{H}, \mathrm{Ar}-\underline{\mathrm{H}}), 7.35$ (d, J = 8.2 Hz, 1H, Ar- $\underline{\mathrm{H}}), 7.32(\mathrm{~s}, 1 \mathrm{H}, \mathrm{Ar}-\underline{\mathrm{H}})$, $7.26(\mathrm{~d}, J=7.9 \mathrm{~Hz}, 1 \mathrm{H}, \mathrm{Ar}-\underline{\mathrm{H}}), 7.22(\mathrm{~d}, J=7.4 \mathrm{~Hz}, 1 \mathrm{H}, \mathrm{Ar}-\underline{\mathrm{H}}), 7.06(\mathrm{t}, J=7.6 \mathrm{~Hz}, 1 \mathrm{H}, \mathrm{Ar}-\underline{\mathrm{H}})$, $6.94(\mathrm{t}, J=7.5 \mathrm{~Hz}, 1 \mathrm{H}, \mathrm{Ar}-\underline{\mathrm{H}}), 5.25(\mathrm{t}, J=7.1 \mathrm{~Hz}, 1 \mathrm{H}, \mathrm{CH}), 4.11-3.95\left(\mathrm{~m}, 2 \mathrm{H}, \mathrm{CH}_{2}\right) ;{ }^{13} \mathrm{C}-\mathrm{NMR}$ $\left(101 \mathrm{MHz}, \mathrm{DMSO}-d_{6}\right) \delta 196.8$ (CO), 150.8, 139.6, 138.5, 138.2, 136.4, 135.3, 130.1, 128.8, 126.1, $124.1,123.5,123.1,122.6,122.2,121.1,120.3,118.7,118.6,116.8,111.6,44.6(\underline{\mathrm{CH}}), 33.4\left(\mathrm{CH}_{2}\right)$; IR $\left(\mathrm{KBr}, \mathrm{cm}^{-1}\right) \nu_{\max }=3383,3055,2954,2921,2852,1676,1583,1483,1454,1402,1356,1328$, 1261, 1194; [Anal. Calcd. for $\mathrm{C}_{25} \mathrm{H}_{18}$ CINOS: C, 72.19; H, 4.36; N, 3.37; Found: C, 72.05; H, 4.24; N, 3.33]; LC/MS (ESI, $m / z$ ): $416.10[\mathrm{M}+\mathrm{H}]^{+}$, exact mass 415.08 for $\mathrm{C}_{25} \mathrm{H}_{18} \mathrm{ClNOS}$.

\subsection{Synthesis of 3-(Benzo[b]thiophen-2-yl)-1-(4-fluorophenyl)-3-(1H-indol-3-yl)propan-1-one} (3p)

Following the general procedure (GP1) chalcone 1k (141 mg, $0.5 \mathrm{mmol})$ indole 2a (64 mg, $0.55 \mathrm{mmol}$ ) produces Friedel-Crafts product-3p (yield $164 \mathrm{mg}, 82 \%$ ); m.p. 142-143 ${ }^{\circ} \mathrm{C} ;{ }^{1} \mathrm{H}-\mathrm{NMR}\left(400 \mathrm{MHz}, \mathrm{DMSO}-d_{6}\right) \delta 10.98(\mathrm{~s}, 1 \mathrm{H}, \mathrm{NH}), 8.14(\mathrm{dd}, J=8.5,5.6 \mathrm{~Hz}, 2 \mathrm{H}, \mathrm{Ar}-\underline{\mathrm{H}})$, $7.76(\mathrm{~d}, J=8.0 \mathrm{~Hz}, 1 \mathrm{H}, \mathrm{Ar}-\underline{\mathrm{H}}), 7.68(\mathrm{~d}, J=7.9 \mathrm{~Hz}, 1 \mathrm{H}, \mathrm{Ar}-\underline{\mathrm{H}}), 7.55(\mathrm{~d}, J=8.0 \mathrm{~Hz}, 1 \mathrm{H}, \mathrm{Ar}-\underline{\mathrm{H}})$, $7.43(\mathrm{~s}, 1 \mathrm{H}, \mathrm{Ar}-\underline{\mathrm{H}}), 7.40-7.30(\mathrm{~m}, 4 \mathrm{H}, \mathrm{Ar}-\underline{\mathrm{H}}), 7.30-7.24(\mathrm{~m}, 1 \mathrm{H}, \mathrm{Ar}-\underline{\mathrm{H}}), 7.21(\mathrm{t}, J=7.6 \mathrm{~Hz}, 1 \mathrm{H}$, Ar- $\underline{\mathrm{H}}), 7.06(\mathrm{t}, J=7.6 \mathrm{~Hz}, 1 \mathrm{H}, \mathrm{Ar}-\underline{\mathrm{H}}), 6.93(\mathrm{t}, J=7.5 \mathrm{~Hz}, 1 \mathrm{H}, \mathrm{Ar}-\underline{\mathrm{H}}), 5.25(\mathrm{t}, J=7.2 \mathrm{~Hz}, 1 \mathrm{H}$, $\mathrm{C} \underline{\mathrm{H}}), 4.02\left(\mathrm{dd}, J=11.1,7.2 \mathrm{~Hz}, 2 \overline{\mathrm{H}}, \mathrm{CH}_{2}\right) ;{ }^{13} \mathrm{C}-\mathrm{NMR}\left(101 \mathrm{MHz}, \mathrm{DMSO}-d_{6}\right) \delta 196.4(\underline{\mathrm{CO}})$, $166.3 \& 163.8\left(\mathrm{C}_{1}-\mathrm{F}, J_{\mathrm{C}-\mathrm{F}}=250.2 \mathrm{~Hz}\right), 150.8,139.6,138.5,136.4,133.4 \& 133.4\left(\mathrm{C}_{4}-\mathrm{F}, J_{\mathrm{C}-\mathrm{F}}\right.$ $=2.9 \mathrm{~Hz}), 131.2,126.1,124.1,123.6,123.0,122.5,122.5,122.2,121.1,120.2 \& 120.2\left(\mathrm{C}_{3}-\mathrm{F}\right.$, $\left.J_{\mathrm{C}-\mathrm{F}}=6.3 \mathrm{~Hz}\right), 118.5,116.9,115.8 \& 115.6\left(\mathrm{C}_{2}-\mathrm{F}, J_{\mathrm{C}-\mathrm{F}}=22.0 \mathrm{~Hz}\right), 111.5,44.5(\underline{\mathrm{CH}}), 33.5\left(\underline{\mathrm{CH}}_{2}\right)$; IR $\left(\mathrm{KBr}, \mathrm{cm}^{-1}\right) v_{\max }=3400,3059,2904,1670,1591,1502,1454,1411,1356,1335,1226,1153$; [Anal. Calcd. for $\mathrm{C}_{25} \mathrm{H}_{18} \mathrm{FNOS}$ : C, 75.16; H, 4.54; N, 3.51; Found: C, 75.26; H, 4.43; N, 3.47]; LC/MS (ESI, $m / z): 400.13[\mathrm{M}+\mathrm{H}]^{+}$, exact mass 399.11 for $\mathrm{C}_{25} \mathrm{H}_{18} \mathrm{FNOS}$.

3.18. Synthesis of 3-(Benzo[b]thiophen-2-yl)-3-(1H-indol-3-yl)-1-(4(trifluoromethyl)phenyl)propan-1-one (3q)

Following the general procedure (GP1) chalcone 11 (162 mg, $0.5 \mathrm{mmol})$ indole 2a (64 mg, $0.55 \mathrm{mmol}$ ) produces Friedel-Crafts product-3q (yield $171 \mathrm{mg}, 76 \%$ ); m.p. 165-166 ${ }^{\circ} \mathrm{C} ;{ }^{1} \mathrm{H}-\mathrm{NMR}\left(400 \mathrm{MHz}, \mathrm{DMSO}-d_{6}\right) \delta 10.98(\mathrm{~d}, J=2.5 \mathrm{~Hz}, 1 \mathrm{H}, \mathrm{NH}), 8.23(\mathrm{~d}, J=8.1 \mathrm{~Hz}, 2 \mathrm{H}$, $\operatorname{Ar}-\underline{\mathrm{H}}), 7.89(\mathrm{~d}, J=8.3 \mathrm{~Hz}, 2 \mathrm{H}, \operatorname{Ar}-\underline{\mathrm{H}}), 7.77(\mathrm{~d}, J=8.0 \mathrm{~Hz}, 1 \mathrm{H}, \operatorname{Ar}-\underline{\mathrm{H}}), 7.69(\mathrm{~d}, J=7.9 \mathrm{~Hz}, 1 \mathrm{H}$, $\operatorname{Ar}-\underline{\mathrm{H}}), 7.56(\mathrm{~d}, J=8.0 \mathrm{~Hz}, 1 \mathrm{H}, \mathrm{Ar}-\underline{\mathrm{H}}), 7.43(\mathrm{~d}, J=2.6 \mathrm{~Hz}, 1 \mathrm{H}, \mathrm{Ar}-\underline{\mathrm{H}}), 7.35(\mathrm{~d}, J=8.6 \mathrm{~Hz}, 2 \mathrm{H}$, Ar- $\underline{\mathrm{H}}), 7.30-7.19(\mathrm{~m}, 2 \mathrm{H}, \mathrm{Ar}-\underline{\mathrm{H}}), 7.06(\mathrm{t}, J=7.6 \mathrm{~Hz}, 1 \mathrm{H}, \mathrm{Ar}-\underline{\mathrm{H}}), 6.94(\mathrm{t}, J=7.4 \mathrm{~Hz}, 1 \mathrm{H}, \mathrm{Ar}-\underline{\mathrm{H}})$, $5.26(\mathrm{t}, J=7.1 \mathrm{~Hz}, 1 \mathrm{H}, \mathrm{CH}), 4.10\left(\mathrm{t}, J=7.4 \mathrm{~Hz}, 2 \mathrm{H}, \mathrm{CH}_{2}\right) ;{ }^{13} \mathrm{C}-\mathrm{NMR}\left(101 \mathrm{MHz}, \mathrm{DMSO}-d_{6}\right)$ $\delta 197.3$ (드), 150.6, 139.7, 139.5, 138.5, 136.4, 132.7, 132.4, 128.9, 126.1, 125.70, 124.1, 123.6, $123.0,122.5,122.1,121.2,120.2,118.6,116.7,111.5,44.9(\underline{\mathrm{CH}}), 33.4\left(\mathrm{CH}_{2}\right) ; \mathrm{IR}\left(\mathrm{KBr}, \mathrm{cm}^{-1}\right)$ $v_{\max }=3458,3415,3050,2960,2902,1689,1454,1409,1319,1261,1166$; [Anal. Calcd. for $\mathrm{C}_{26} \mathrm{H}_{18} \mathrm{~F}_{3} \mathrm{NOS}$ : C, 69.47; H, 4.04; N, 3.12; Found: C, 69.59; H, 3.97; N, 3.07]; LC/MS (ESI, $m / z): 450.11[\mathrm{M}+\mathrm{H}]^{+}$, exact mass 449.11 for $\mathrm{C}_{26} \mathrm{H}_{18} \mathrm{~F}_{3} \mathrm{NOS}$.

\subsection{Synthesis of 3-(Benzofuran-2-yl)-3-(1H-indol-3-yl)-1-(2-methoxyphenyl)propan-1-one (3r):}

Following the general procedure (GP1) chalcone $\mathbf{1 f}(139 \mathrm{mg}, 0.5 \mathrm{mmol})$ indole 2a (64 mg, $0.55 \mathrm{mmol}$ ) produces Friedel-Crafts product-3r (yield $158 \mathrm{mg}, 80 \%$ ); m.p. 67-68 ${ }^{\circ} \mathrm{C}$; ${ }^{1} \mathrm{H}-\mathrm{NMR}\left(400 \mathrm{MHz}, \mathrm{DMSO}-d_{6}\right) \delta 10.96$ (d, J = $\left.2.5 \mathrm{~Hz}, 1 \mathrm{H}, \mathrm{NH}\right), 7.56-7.48$ (m, 3H, Ar- $\left.\underline{\mathrm{H}}\right)$, 7.47-7.40 (m, 2H, Ar- $\underline{\mathrm{H}}), 7.35(\mathrm{~d}, J=8.1 \mathrm{~Hz}, 1 \mathrm{H}, \mathrm{Ar}-\underline{\mathrm{H}}), 7.26(\mathrm{~d}, J=2.6 \mathrm{~Hz}, 1 \mathrm{H}, \mathrm{Ar}-\underline{\mathrm{H}}), 7.16$ $(\mathrm{dd}, J=8.1,4.9 \mathrm{~Hz}, 3 \mathrm{H}, \mathrm{Ar}-\underline{\mathrm{H}}), 7.06(\mathrm{t}, J=7.4 \mathrm{~Hz}, 1 \mathrm{H}, \mathrm{Ar}-\underline{\mathrm{H}}), 6.96(\mathrm{dt}, J=14.9,7.2 \mathrm{~Hz}, 2 \mathrm{H}$, $\operatorname{Ar}-\underline{\mathrm{H}}), 6.62(\mathrm{~s}, 1 \mathrm{H}, \mathrm{Ar}-\underline{\mathrm{H}}), 5.06(\mathrm{t}, J=7.2 \mathrm{~Hz}, 1 \mathrm{H}, \mathrm{C} \underline{\mathrm{H}}), 3.94\left(\mathrm{dd}, J=17.1,7.6 \mathrm{~Hz}, 1 \mathrm{H}, \mathrm{CH}_{2(\mathrm{a})}\right)$, $3.86\left(\mathrm{~s}, 3 \mathrm{H}, \mathrm{OC}_{3}\right), 3.78\left(\mathrm{dd}, J=17.0,7.1 \mathrm{~Hz}, 1 \mathrm{H}, \underline{\mathrm{CH}}_{2(\mathrm{~b})}\right) ;{ }^{13} \mathrm{C}-\mathrm{NMR}\left(101 \mathrm{MHz}, \mathrm{DMSO}-d_{6}\right)$ $\delta 199.5$ (CO), 160.9, 158.0, 153.9, 136.3, 133.6, 129.6, 129.4, 128.4, 127.7, 126.0, 122.9, 122.7, 
$121.1,120.6,120.4,118.6,118.4,114.2,112.5,111.7,110.6,101.9,55.8\left(\mathrm{OCH}_{3}\right), 47.1(\underline{\mathrm{CH}}), 31.9$ $\left(\mathrm{CH}_{2}\right) ; \mathrm{IR}\left(\mathrm{KBr}, \mathrm{cm}^{-1}\right) v_{\max }=3408,3051,2918,2837,1666,1599,1483,1454,1430,1340,1286$, 1244, 1161; [Anal. Calcd. for $\mathrm{C}_{26} \mathrm{H}_{21} \mathrm{NO}_{3}$ : C, 78.97; H, 5.35; N, 3.54; Found: C, 78.81; H, 5.19; $\mathrm{N}, 3.39] ; \mathrm{LC} / \mathrm{MS}(\mathrm{ESI}, \mathrm{m} / z)$ : $396.16[\mathrm{M}+\mathrm{H}]^{+}$, exact mass 395.15 for $\mathrm{C}_{26} \mathrm{H}_{21} \mathrm{NO}_{3}$.

3.20. Synthesis of 3-(Benzofuran-2-yl)-3-(5-bromo-1H-indol-3-yl)-1-(2methoxyphenyl)propan-1-one (3s)

Following the general procedure (GP1) chalcone $\mathbf{1 f}(139 \mathrm{mg}, 0.5 \mathrm{mmol})$ 5-bromoindole 2b (108 mg, $0.55 \mathrm{mmol}$ ) produces Friedel-Crafts product-3s (yield $180 \mathrm{mg}, 76 \%$ ); m.p. 60-61 ${ }^{\circ} \mathrm{C} ;{ }^{1} \mathrm{H}-\mathrm{NMR}\left(400 \mathrm{MHz}, \mathrm{DMSO}-d_{6}\right) \delta 11.20(\mathrm{~d}, J=2.3 \mathrm{~Hz}, 1 \mathrm{H}, \mathrm{NH}), 7.72$ (s, 1H, Ar- $\underline{\mathrm{H}}), 7.51(\mathrm{t}, J=7.5 \mathrm{~Hz}, 2 \mathrm{H}, \mathrm{Ar}-\underline{\mathrm{H}}), 7.47-7.41$ (m, 2H, Ar- $\underline{\mathrm{H}}), 7.37-7.31$ (m, 2H, Ar- $\underline{\mathrm{H}}), 7.17$ $(\mathrm{dd}, J=11.8,7.6 \mathrm{~Hz}, 4 \mathrm{H}, \mathrm{Ar}-\underline{\mathrm{H}}), 6.98(\mathrm{t}, J=7.4 \mathrm{~Hz}, 1 \mathrm{H}, \mathrm{Ar}-\underline{\mathrm{H}}), 6.65(\mathrm{~s}, 1 \mathrm{H}, \mathrm{Ar}-\underline{\mathrm{H}}), 5.05(\mathrm{t}$, $J=7.3 \mathrm{~Hz}, 1 \mathrm{H}, \mathrm{C} \underline{\mathrm{H}}), 3.91\left(\mathrm{dd}, J=17.3,7.4 \mathrm{~Hz}, 1 \mathrm{H}, \mathrm{C}_{2(\mathrm{a})}\right), 3.87\left(\mathrm{~s}, 3 \mathrm{H}, \mathrm{OCH}_{3}\right), 3.81(\mathrm{dd}$, $\left.J=17.1,7.3 \mathrm{~Hz}, 1 \mathrm{H}, \underline{\mathrm{CH}}_{2(\mathrm{~b})}\right) ;{ }^{13} \mathrm{C}-\mathrm{NMR}\left(126 \mathrm{MHz}, \mathrm{DMSO}-d_{6}\right) \delta 199.4,160.6,158.1,153.9$, 135.0, 133.7, 129.6, 128.3, 127.9, 127.6, 124.7, 123.6, 123.5, 122.6, 120.8, 120.6, 120.5, 114.0, 113.6, 112.4, 111.2, 110.7, 101.9, 55.8, 47.0, 31.8; IR $\left(\mathrm{KBr}, \mathrm{cm}^{-1}\right) v_{\max }=3320,3045,2915,2857$, $1668,1575,1452,1395,1365,1338,1252$; [Anal. Calcd. for $\mathrm{C}_{26} \mathrm{H}_{20} \mathrm{BrNO}_{3}$ : C, 65.83; $\mathrm{H}, 4.25$; N, 2.95; Found: C, 66.02; H, 4.11; N, 2.86]; LC/MS (ESI, $m / z): 474.07[\mathrm{M}+\mathrm{H}]{ }^{+}$, exact mass 473.06 for $\mathrm{C}_{26} \mathrm{H}_{20} \mathrm{BrNO}_{3}$

\subsection{The Biological Activity Assays Protocols}

Cytotoxicity against BJ Human fibroblast cells, and anti-cancer activity against PC3, HeLa and MCF-7 cancer cell lines were evaluated by following the procedure as described in the literature [25-29] (Supplementary Materials).

\section{Conclusions}

We have successfully synthesized multi-scaffold-based indoles, benzofurans and benzothiophenes. The anti-cancer activity showed promising results which make them candidates for further research. Fluorine atoms apparently play a crucial role in the bioactivity of this class of compounds with $\mathbf{3 b}$ appearing to be the most active member of the series against cervical cancer HeLa $\left(\mathrm{IC}_{50}=8.2 \pm 0.2 \mu \mathrm{M}\right)$ and breast cancer MCF-7 cell lines $\left(\mathrm{IC}_{50}=12.3 \pm 0.04 \mu \mathrm{M}\right)$, whereas hit $3 \mathbf{e}\left(\mathrm{IC}_{50}=7.8 \pm 0.4 \mu \mathrm{M}\right)$ appeared more active against PC3 prostate cancer cell line. The mechanism of action and in vivo study are required to further validate results of in vitro status.

Supplementary Materials: The following are available online, ${ }^{1} \mathrm{H}-\mathrm{NMR}$ and ${ }^{13} \mathrm{C}-\mathrm{NMR}$ for compounds $3 a-3$ s along with the biological activity assays protocols are provided in the Supplementary Materials.

Author Contributions: Conceptualization, A.B. and M.I.C.; methodology, M.S.I.; M.A.; A.M.A.-M.; A.S.A.; S.A.; validation, M.S.I.; M.A.; A.M.A.-M.; A.S.A.; S.A.; formal analysis, M.S.I.; M.A.; A.M.M.A.M.; A.S.A.; S.A.; investigation, M.S.I.; M.A.; A.M.A.-M.; A.S.A.; S.A.; resources, A.B.; data curation, M.S.I.; M.A.; A.M.A.-M.; A.S.A.; writing—original draft preparation, A.B.; and S.Y.; writing-review and editing, M.I.C.; visualization, A.B. and M.I.C.; project administration, M.A.; funding acquisition, A.B. All authors have read and agreed to the published version of the manuscript.

Funding: King Abdulaziz City for Science and Technology, Kingdom of Saudi Arabia, Award Number (14-BIO128-02).

Data Availability Statement: The data presented in this study are available in Supplementary Materials.

Acknowledgments: This Project was funded by the National Plan for Science, Technology and Innovation (MAARIFAH), King Abdulaziz City for Science and Technology, Kingdom of Saudi Arabia, Award Number (14-BIO128-02).

Conflicts of Interest: The authors declare no conflict of interest.

Sample Availability: Samples of the compounds 3a-3s are available from the authors. 


\section{References}

1. Lounasmaa, M.; Tolvanen, A. Simple indole alkaloids and those with a nonrearranged monoterpenoid unit (July 1997 to December 1998). Nat. Prod. Rep. 2000, 17, 175-191. [CrossRef]

2. Kumari, A.; Singh, R.K. Medicinal chemistry of indole derivatives: Current to future therapeutic prospectives. Bioorganic Chem. 2019, 89, 103021. [CrossRef]

3. Noble, R.L.; Beer, C.T.; Cutts, J.H. Role of chance observations in chemotherapy: Vinca rosea. Ann. New York Acad. Sci. 1958, 76, 882-894. [CrossRef]

4. Gueritte, F.; Fahy, J. The Vinca Alkaloids. In Anticancer agents from natural products; Cragg, G.M., Kingston, D.G.I., Newman, D.J., Eds.; CRC Press: Boca Raton, FL, USA, 2005; p. 123.

5. Duflos, A.; Kruczynski, A.; Barret, J.-M. Novel aspects of natural and modified vinca alkaloids. Curr. Med. Chem. Agents 2012, 2, 55-70. [CrossRef]

6. Sharma, V.; Kumar, P.; Pathak, D. Biological importance of the indole nucleus in recent years: A comprehensive review. J. Heterocycl. Chem. 2010, 47, 491-502. [CrossRef]

7. Brancale, A.; Silvestri, R. Indole, a core nucleus for potent inhibitors of tubulin polymerization. Med. Res. Rev. 2007, 27, 209-238. [CrossRef]

8. Gul, W.; Hamann, M.T. Indole alkaloid marine natural products: An established source of cancer drug leads with considerable promise for the control of parasitic, neurological and other diseases. Life Sci. 2005, 78, 442-453. [CrossRef]

9. Rodrigues de, S.A.F.; Barreiro, E.J.; Fraga, C.A.M. From Nature to Drug Discovery: The Indole Scaffold as a 'Privileged Structure'. Mini Rev Med Chem. 2009, 9, 782-793. [CrossRef]

10. Noble, R.L. The discovery of the Vinca alkaloids—chemotherapeutic agents against cancer. Biochem. Cell Biol. 1990, 68, 1344-1351. [CrossRef]

11. Varoglu, M.; Corbett, T.H.; Valeriote, F.A.; Crews, P. Asperazine, a selective cytotoxic alkaloid from a sponge-derived culture of Aspergillus niger. J. Org. Chem. 1997, 62, 7078-7079. [CrossRef]

12. Valeriote, F.; Corbett, T.; Lorusso, P.; Moore, R.E.; Scheuer, P.; Patterson, G.; Paul, V.; Grindey, G.; Bonjouklian, R.; Pearce, H.; et al. Discovery of anticancer agents from natural products. Int. J. Pharmacogn. 1995, 33, 59-66. [CrossRef]

13. Valeriote, F.; Corbett, T.; Edelstein, M.; Baker, L. New in vitro screening model for the discovery of antileukemic anticancer agents. Cancer Investig. 1996, 14, 124-141. [CrossRef]

14. Govek, S.P.; Overman, L.E. Total synthesis of (+)-asperazine. Tetrahedron 2007, 63, 8499-8513. [CrossRef]

15. Kohmoto, S.; Kashman, Y.; McConnell, O.J.; Rinehart, J.; Wright, A.; Koehn, F. Dragmacidin, a new cytotoxic bis (indole) alkaloid from a deep water marine sponge, Dragmacidon sp. J. Org. Chem. 1988, 53, 3116-3118. [CrossRef]

16. Sung, H.; Ferlay, J.; Siegel, R.L.; Laversanne, M.; Soerjomataram, I.; Jemal, A.; Bray, F. Global cancer statistics 2020: GLOBOCAN estimates of incidence and mortality worldwide for 36 cancers in 185 countries. CA Cancer J. Clin. 2021, 68, 394-424. [CrossRef]

17. WHO (February 2006). Cancer. World Health Organization. Retrieved on 2007-06-25. Available online: https://www.cancer.org/ research/cancer-facts-statistics/global (accessed on 1 June 2020).

18. Garcia, M.; Jemal, A.; Ward, E.M. Global Cancer Facts and Figures 2007; American Cancer Society: Atlanta, GA, USA, 2007. Available online: https:/ / www.cancer.org/research/cancer-facts-statistics/global (accessed on 1 June 2020).

19. World Health Organization. Preventing Chronic Diseases: A Vital Investment; WHO: Geneva, Switzerland, 2005.

20. Barakat, A.; Islam, M.S.; Al-Majid, M.A.; Al-Othman, Z.A. Highly enantioselective Friedel-Crafts alkylation of indoles with $\alpha$, $\beta$-unsaturated ketones with simple Cu (II)-oxazoline-imidazoline catalysts. Tetrahedron 2013, 69, 5185-5192. [CrossRef]

21. Islam, M.S.; Al-Majid, A.M.; Al-Othman, Z.A.; Barakat, A. Highly enantioselective Friedel-Crafts alkylation of indole with electron deficient trans- $\beta$-nitroalkenes under simple Zn(II)-oxazoline-imidazoline catalysts. Tetrahedron Asymmetry 2014, 25, 245-251. [CrossRef]

22. Barakat, A.; Al-Majid, A.M.A.; Al-Qahatany, F.M.; Islam, M.S.; Al-Agamy, M.H. Synthesis, characterization and antimicrobial activity of novel pharmacophores incorporating imidazoline-oxazoline scaffold. Bull. Korean Chem. Soc. 2014, 35, 562-568. [CrossRef]

23. Badria, F.A.; Atef, S.; Al-Majid, A.M.; Islam, M.S.; Ali, M.; Elshaier, Y.A.M.M.; Ghabbour, H.A.; Barakat, A. Synthesis and inhibitory effect of some indole-pyrimidine-based hybrid heterocycles on $\alpha$-glucosidase and $\alpha$-amylase as potential hypoglycemic agents. ChemistryOpen 2019, 8, 1288-1297. [CrossRef] [PubMed]

24. Badria, F.A.; Soliman, S.M.; Atef, S.; Islam, M.S.; Al-Majid, A.M.; Dege, N.; Ghabbour, H.A.; Ali, M.; El-Senduny, F.F.; Barakat, A. Anticancer indole-based chalcones: A structural and theoretical analysis. Molecules 2019, 24, 3728. [CrossRef]

25. Foye, W.O.; Lemke, T.L.; Williams, D.A. Principles of Medicinal Chemistry, 4th ed.; Williams and Wilkins: Philadelphia, PA, USA, $2002 ;$ p. 822.

26. Mannerström, M.; Toimela, T.; Sarkanen, J.-R.; Heinonen, T. Human BJ Fibroblasts is an Alternative to Mouse BALB/c 3T3 Cells inIn VitroNeutral Red Uptake Assay. Basic Clin. Pharmacol. Toxicol. 2017, 121, 109-115. [CrossRef] [PubMed]

27. Price, P.; McMillan, T.J. Use of the tetrazolium assay in measuring the response of human tumor cells to ionizing radiation. Cancer Res. 1990, 50, 1392-1396. Available online: https://cancerres.aacrjournals.org/content/canres/50/5/1392.full.pdf (accessed on 1 June 2020). 
28. Scudiero, D.A.; Shoemaker, R.H.; Paull, K.D.; Monks, A.; Tierney, S.; Nofziger, T.H.; Currens, M.J.; Seniff, D.; Boyd, M.R. Evaluation of a soluble tetrazolium/formazan assay for cell growth and drug sensitivity in culture using human and other tumor cell lines. Cancer Res. 1988, 48, 4827-4833.

29. Mosmann, T. Rapid colorimetric assay for cellular growth and survival: Application to proliferation and cytotoxicity assays. J. Immunol. Methods 1983, 65, 55-63. [CrossRef] 